UNIVERSIDADE DE SÃO PAULO

FACULDADE DE FILOSOFIA, CIÊNCIAS E LETRAS DE RIBEIRÃO PRETO

PAULA VERZOLA-OLIVIO

Associações preferenciais e o papel da fêmea nas relações intersexuais em cobaias (Cavia porcellus)

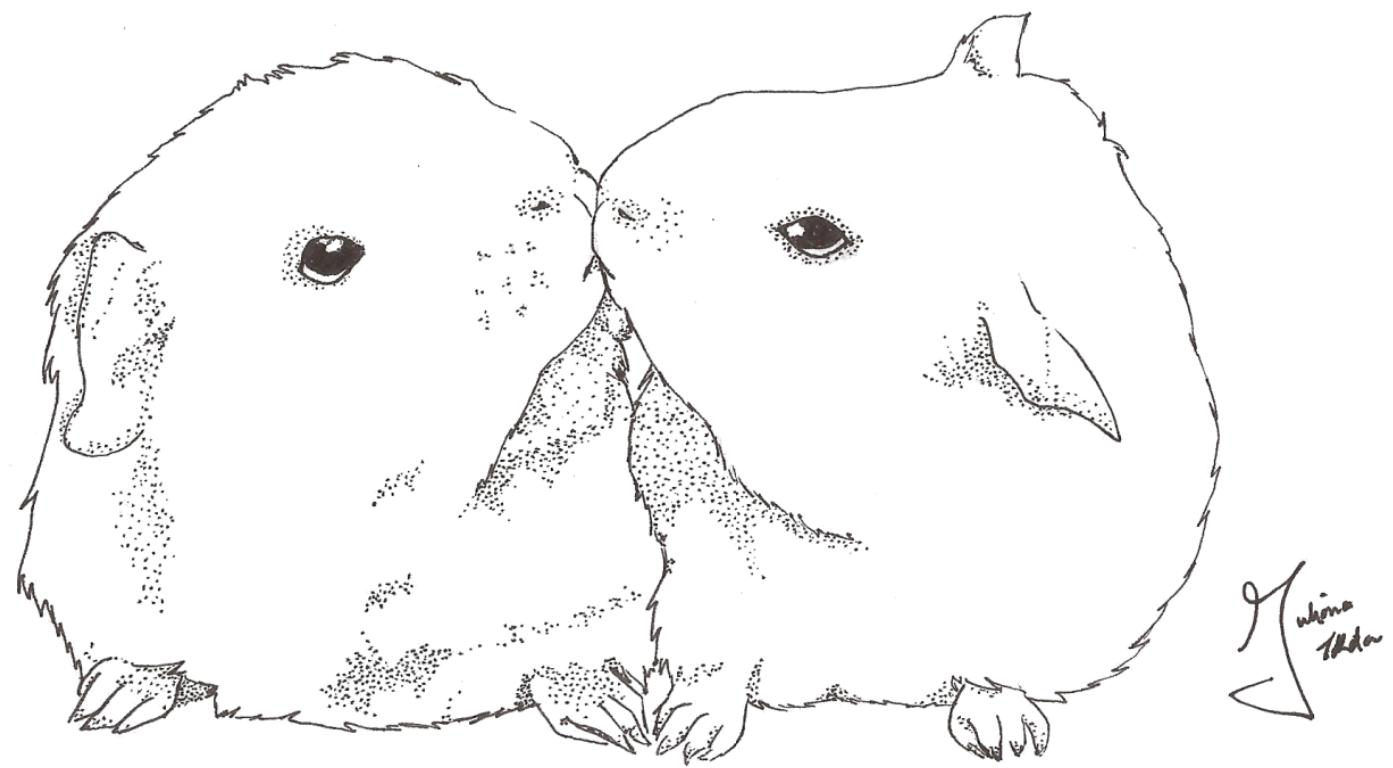

Ribeirão Preto 
Faculdade de Filosofia, Ciências e Letras de Ribeirão Preto

PAULA VERZOLA-OLIVIO

\section{Associações preferenciais e o papel da fêmea nas relações intersexuais em cobaias (Cavia porcellus)}

Dissertação apresentada à Faculdade de Filosofia, Ciências e Letras de Ribeirão Preto, Universidade de São Paulo, como parte das exigências para obtenção do título de Mestre em Ciências.

Área de Concentração: Psicobiologia

Orientadora: Profa. Dra. Patrícia Ferreira Monticelli

Ribeirão Preto 
Autorizo a reprodução e divulgação total ou parcial deste trabalho, por qualquer meio convencional ou eletrônico, para fins de estudo e pesquisa, desde que citada a fonte.

Verzola-Olivio, Paula.

Associações preferenciais e o papel das fêmeas nas relações intersexuais em cobaias (Cavia porcellus).

Ribeirão Preto, 2016.

$58 \mathrm{p}$.

Dissertação de Mestrado. Faculdade de Filosofia, Ciências e Letras de Ribeirão Preto. Universidade de São Paulo.

Área de Concentração: Psicobiologia.

Orientadora: Profa. Dra. Patrícia Ferreira Monticelli.

1. Comportamento social. 2. Vínculo social. 3. Escolha da fêmea. 4. Redes Sociais. 5. Roedores caviomorfos. 
Às cobaias, com amor. 


\section{AgRAdeCimentos}

Às minhas queridas cobaias, que me permitem tentar entender um pouco mais desse rico mundo em que vivem. Foi amor ao primeiro assobio!

À minha família, meus pais Luiz e Solange, minha irmã Júlia, meu cunhado Johnatan (que também já é da família) e nossa pequena irmãzinha de quatro patas Megan. Pelo apoio incondicional desde o momento em que escolhi ser bióloga e, mais ainda, quando optei pela carreira acadêmica. Pelo amor e carinho dedicados a mim durante toda a minha vida. Obrigada por tudo, sempre!

Às minhas madrinhas e segundas mães Marilisa (Lisa) e Elisete (Dinda) por todo amor e suporte ao longo dos anos, principalmente quando minha mãe não pode estar presente.

À todos os meus amigos, que eu tenho o privilégio de dizer que não são poucos, por compartilharem comigo os bons e maus momentos, por todo suporte, mesmo que indireto, durante as "tragédias" deste Mestrado. Por todas as Penélopes, Churras da Bio, Bares da Filô, almoços, jantares, conversas fiadas e, principalmente, por me aguentarem por todo esse tempo. Por tudo isso e muito mais, agradeço a vocês: Athos, Bárbara, Sté, Larissa, Gui Sabatini, GPS (Carolina), Tolima (Bruno), Vitória, Pedi (Vinícius), Pinky (Eduardo), Trala (Júlia), Tila (Priscila), Fresno (Patrick), Maomé (Fernando), Yoshi (Maurício), Fralda (André), Portuga (Caio), Johny (Robson), Neto. A ordem dos nomes não reflete o tamanho do carinho. Todos moram no meu coração.

À GPS (Carolina), um agradecimento especial pelas revisões acadêmicas ao longo destes anos, além da amizade que perdura desde o início da graduação.

Ao Yoshi (Maurício), também um agradecimento especial por ter iniciado a campanha que me ajudou a adquirir os animais para minha pesquisa.

À todos aqueles que contribuíram financeiramente para que eu pudesse adquirir os animais de minha pesquisa. Em tempos de cortes na pesquisa, a ajuda de vocês foi fundamental. Maurício Nagata Yoshida, Caio de Castro Freire, Luziene Aparecida Grandi, Brucce Sanderson, Cristiane Contin, Juliana Takata, Vinícius Anelli, Raphael Pieri, Rafael Castro, Carolina 


\section{Verruma, Cintia Suzuki, Bárbara Matos, Bruno César Vieira, Caio Cruz, Priscila Rothier, Eduardo Borges, Adriana Sicuto.}

À minha querida orientadora Patrícia, por todo carinho, apoio e confiança ao longo destes anos. Pela paciência comigo na reta final desta dissertação, que não foi fácil. Por sempre acreditar no meu potencial e por ser sempre mais do que uma orientadora para mim e as meninas do EBAC. E que venham os próximos quatro anos do Doutorado.

À todas as meninas do Laboratório de Etologia e Bioacústica pelo companheirismo, dentro e fora do Lab., e disposição em ajudar sempre que precisei (e não foram poucas vezes!). Agradeço especialmente Cintia, Adriana e Ju pela amizade que construímos, a Laís por ter sido minha companheira de Redes nestes últimos meses e as novas companheiras Tainá e Stella pelo cuidado que tiveram com meus "bebês" quando não pude estar presente.

Ao Professor Fernando Frei pelas análises estatísticas deste trabalho e por ter aceitado me coorientar no Doutorado.

À Professora Andreia Schimidt pela ajuda na montagem do desenho experimental dos meus testes e pelas palavras de incentivo sempre que nos encontramos.

Ao Maurício Cantor, pela ajuda com a análise das redes sociais.

Aos técnicos da Psicobiologia João e Rodrigo por todo o apoio no cuidado com os animais.

À secretária do Programa de Pós-graduação em Psicobiologia, Renata Vicentini, pelo apoio acadêmico ao longo do Mestrado.

Ao Programa de Pós-graduação em Psicobiologia pela oportunidade de iniciar minha vida acadêmica.

Aos funcionários do Biotério Central do campus, diretor Helder Tambelini, veterinário Alexandre e Sr. Melk, pelo empréstimo do espaço para a construção do cercado das cobaias e pelo apoio com os animais durante o Mestrado. 
Ao veterinário César Branco, do Bosque Zoológico Municipal Fábio Barreto, pelo cuidado com as minhas cobaias e a disposição certa em nos ajudar.

À Faculdade de Filosofia, Ciências e Letras de Ribeirão Preto, pelo acolhimento desde a Graduação.

À Comissão de Ética em Pesquisa Animal (CEPA -IP/USP) pela autorização concedida.

À CAPES pela bolsa e apoio financeiro concedido.

A todos aqueles que, de alguma forma, contribuíram para este trabalho. 
Fortes são aqueles que transformam em luz o que é escuridão.

(Siga o som - Forfun) 


\section{RESUMO}

VERZOLA-OLIVIO, P. Associações preferenciais e o papel da fêmea nas relações intersexuais em cobaias (Cavia porcellus). 2016. 58p. Dissertação de Mestrado em Psicobiologia. - Faculdade de Filosofia, Ciências e Letras de Ribeirão Preto, Universidade de São Paulo, Ribeirão Preto, 2016.

As interações entre os membros de um grupo social possuem um importante efeito sobre os padrões de competição, cooperação e acasalamento dos indivíduos, interferindo, assim, na aptidão dos mesmos. Os indivíduos podem se relacionar de maneira preferencial, estabelecendo vínculos sociais. A manutenção destes vínculos pode aumentar longevidade e também o sucesso reprodutivo. Historicamente, houve uma tendência em se investigar a formação de associações intersexuais e, consequentemente a seleção de parceiros, através do ponto de vista do macho, restando à fêmea um papel passivo neste processo. O objetivo deste trabalho foi investigar a formação de associações intra e intersexuais em cobaias (Cavia porcellus) vivendo em colônia e verificar se em ambiente controlado, onde a interferência dos machos entre si e sobre as fêmeas era limitada, as fêmeas demonstram preferência por um macho específico, dando indícios de sua participação na formação das associações intersexuais. Para isto, a estrutura social das cobaias na colônia foi definida por meio do cálculo do índice de associação entre os indivíduos e de parâmetros de redes sociais (força e centralidade). Em seguida, a preferência das fêmeas foi testada em um cercado experimental com três compartimentos, no qual dois abrigavam machos restritos a seu ambiente pelo uso de coleira e guia, e um deles permanecia vazio. As fêmeas possuíam acesso livre a todos os compartimentos por duas horas. A análise da preferência das fêmeas se deu pela comparação do tempo que permaneceram em cada um dos compartimentos (Testes de Mann-Whitney e Kruskal-Wallis, nível de significância: 5\%). As cobaias formaram associações preferenciais intra e intersexuais, sendo as associações entre as fêmeas mais fortes do que aquelas entre machos ou entre fêmeas e machos quando a colônia era composta por um número maior de indivíduos. Nas relações intersexuais, as fêmeas apresentaram relações mais fortes com dois dos machos em relação aos outros da colônia. Os resultados do teste de escolha refletiram as associações na colônia: não houve diferença estatística no tempo de permanência das fêmeas com os machos que possuem relações mais fortes com as fêmeas. Um dos machos não foi preferido em nenhum dos testes e de modo geral, as fêmeas passaram mais tempo no compartimento vazio do que acompanhadas dos machos. Os resultados encontrados sobre estrutura social, com a formação de associações preferenciais e teste de escolha indicam que as fêmeas apresentam preferência por machos específicos, dando indícios de sua participação na formação das associações intersexuais, e possivelmente, na seleção de parceiros.

Palavras-chave: comportamento social, vínculo social, escolha da fêmea, redes sociais, roedores caviomorfos. 


\begin{abstract}
VERZOLA-OLIVIO, P. Preferential associations and the role of females in intersexual relationships in guinea pigs (Cavia porcellus). 2016. 58p. Dissertação de Mestrado em Psicobiologia. - Faculdade de Filosofia, Ciências e Letras de Ribeirão Preto, Universidade de São Paulo, Ribeirão Preto, 2016.

Interactions among members of a social group have an important consequence in competition, cooperation and mating patterns, interfering in their fitness. Animals can associate preferentially and stablish social bonds. Bond maintenance can increase lifespan and reproductive success. Historically, there is a tendency in investigating male-female relationships and, consequently, mate selection, through male view, placing females in a passive position in this process. This research aimed to investigate the formation of intra and intersexual relationships in guinea pigs (Cavia porcellus) living in colony and verify if, in a controlled environment, where male interference were limited, females would prefer a specific male, indicating an active position in intersexual relationships. The guinea pig social structure was defined using the simple ratio association index and the social network analysis. Female preference was tested in a three partitions fenced, the central was empty and the laterals had a male restricted to it by guinea-pig collar. Females were free to move around all during 2 hours. Female preference analysis was made by comparisons between female time in each partition (Mann Whitney and Kruskal-Wallis, significance: 5\%). Results showed that in colony females make intra and inter preferential associations, strongest among females-than among male-male or female-male in a higher number of individuals in the colony. In femalemale associations, females had stronger relationship with two males from their colony. Results of preference tests reflect association preferences in colony: there were no difference in female time with the two prefered males of the colony. The third male was never chosen, and females prefered to spend more time in the empty partition. Results about social structure with association preferences, and in preference tests show the active role of females in intersexual associations and, possibly, in mate selection.
\end{abstract}

Keywords: social behaviour, social bond, female choice, social networks, caviomorph rodents. 


\section{LISTA DE FIGURAS}

Figura 3.1. Exemplos de animais em proximidade espacial considerada como associação para o cálculo do Índice de Associação. (a) díade forrageando junta; (b) díade explorando o ambiente; (c) contato focinho-focinho entre a díade. Desenhos de Juliana Takata com base nas filmagens da colônia. 22

Figura 3.2. Imagem do cercado utilizado para o teste de escolha, retirada de uma das filmagens feitas durantes os testes. Nos cercados das extremidades encontram-se os machos (Latrel - acima, George - abaixo), presos por coleiras, enquanto a fêmea (Marin - centro) pode se locomover livremente por todos os compartimentos através de aberturas nas divisórias, indicada na imagem pela seta vermelha. 26

Figura 4.1. Rede Social entre as cobaias em colônia na Situação 1. Círculos representam as fêmeas e quadrados, os machos. As linhas mais espessas representam as associações preferenciais (IAdíade>IAmédio). 30

Figura 4.2. Rede Social entre as cobaias em colônia na Situação 2. Círculos representam as fêmeas e quadrados, os machos. As linhas mais espessas representam as associações preferenciais (IAdíade>IAmédio).

Figura 4.3. Resultado das Análises de Redes Sociais. Valores de Força e Centralidade do Autovetor para as cobaias (Cavia porcellus) adultas nas duas variações da colônia: Situação 1 (a) e Situação 2 (b). 32

Figura 4.4. Quantidade de associações preferenciais formadas por cada cobaia (Cavia porcellus) adultas na colônia nas duas variações da colônia: Situação 1 (a) e Situação 2 (b).

Figura 4.5. Representação da estrutura social das cobaias estudadas neste trabalho com base nos valores de IA, força e centralidade calculados para cada indivíduo. Círculos representam as fêmeas e quadrados representam os machos. A posição dos indivíduos se refere aos valores de centralidade do autovetor: quanto mais próximo ao centro, mais central é o indivíduo na estrutura da colônia. $\mathrm{O}$ tamanho dos símbolos é referente à força do indivíduo: quanto maior o símbolo, mais alto o valor de força do indivíduo. A espessura das linhas que conectam os indivíduos é referente aos valores de IA: quanto mais espessa a linha, mais forte é a associação entre os indivíduos. 35

Figura 4.6. Representação gráfica da proporção de tempo que as fêmeas permaneceram em cada compartimento do cercado experimental, que continha um dos machos ou estava vazio no teste de escolha nos diferentes pareamentos realizados. (A) Comparação entre o tempo que as fêmeas permaneceram sozinhas e o tempo que elas permaneceram com os machos (soma do tempo dos dois machos presentes em cada pareamento); (B) Comparação do tempo que as fêmeas permaneceram com cada um dos machos e sozinhas no pareamento Chocolate $\mathrm{x}$ Latrel; (C) Comparação do tempo que as fêmeas permaneceram com cada um dos machos e sozinhas no pareamento Chocolate x George; (D) Comparação do tempo que as fêmeas permaneceram com cada um dos machos e sozinhas no pareamento Latrel x George. 37 


\section{LISTA DE TABELAS}

Tabela 3.1. Identificação dos animais que compuseram a colônia ao longo da pesquisa, com nome, sexo e idade, e indicação da data em que cada indivíduo nasceu (para os jovens) ou que foi inserido (para os adultos) na colônia

Tabela 4.1. Resultado do teste de preferência e/ou evitação para as associações das cobaias (Cavia porcellus) nas duas variações da colônia. Valores reais de desvio padrão (SD) maiores que os randômicos e $p<0,05$ rejeitam a hipótese nula de que as associações entre os indivíduos são aleatórias na Situação 1 e na Situação 2. 28

Tabela 4.2. Valores dos Índices de Associação (IA) das díades que apresentam associação preferencial ( IA $_{\text {díade }}>\mathrm{IA}_{\text {médio }}$ ) entre cobaias (Cavia porcellus) adultas nas duas variações da colônia. * representa as associações intersexuais.

Tabela 4.3. Média e desvio padrão, entre parênteses, dos Índices de Associação intra e inter classes e resultado do Teste de Mantel para comparação das diferenças entre associações intra- e intersexuais entre cobaias (Cavia porcellus) adultas nas duas variações da colônia. F$\mathrm{F}$ representa a associação entre fêmeas, M-M representa a associação entre machos e F-M representa a associação entre fêmeas e machos. Valores positivos para $t$ e correlação de matrizes e $p$ próximo a 1 rejeitam a hipótese nula do teste de que não há diferença entre as associações intra e inter classes.

Tabela 4.4. Comparação entre os postos médios do tempo que as fêmeas de cobaia (Cavia porcellus) passaram sozinhas no compartimento central do cercado experimental em relação ao tempo que passaram com os machos presentes nos testes de escolha segundo o teste de Mann-Whitney (nível de significância: 5\%) 36

Tabela 4.5. Comparação entre os postos médios do tempo que as fêmeas permaneceram com cada um dos machos nos diferentes pareamentos realizados nos testes de escolha segundo teste de Kruskal-Wallis seguido de post-hoc Student-Newman-Keuls (nível de significância: $5 \%$ ). 36

Tabela 4.6. Média, mediana, valor mínimo e valor máximo da porcentagem de tempos que cada fêmea permaneceu com um dos machos nos diferentes pareamentos. 


\section{SUMÁRIO}

1. INTRODUÇÃ̃O ....................................................................... 13

2. OBJetivos E Hipóteses ....................................................... 18

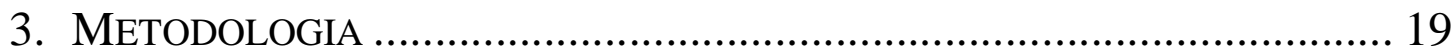

3.1 ANIMAIS EXPERIMENTAIS E MANUTENÇÃO .............................. 19

3.2 FORMAÇÃO DE ASSOCIAÇÕES EM COLÔNIA .............................. 20

3.3 TESTE DE PREFERÊNCIA ...................................................... 24

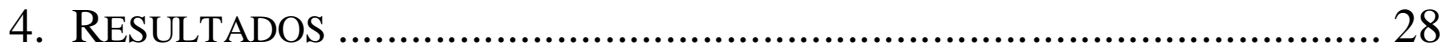

4.1 FORMAÇÃO DE ASSOCIAÇÕES PREFERENCIAIS EM COLÔNIA ........... 28

4.2 TESTE DE PREFERÊNCIA ..................................................... 36

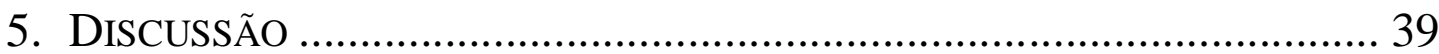

5.1 ASSOCIAÇÕES PREFERENCIAIS EM COLÔNIA .............................. 39

5.2 A ESCOLHA DAS FÊMEAS ................................................ 42

6. CONCLUSÕES FINAIS ........................................................ 46

7. REFERÊNCIAS BIBLIOGRÁFICA ................................................ 47 


\section{INTRODUÇÃO}

Uma sociedade pode ser definida como um grupo de indivíduos que reconhecem uns aos outros, cooperam e competem entre si através de relações organizadas que podem afetar sua aptidão (GARROWAY; BOWMAN; WILSON, 2013). A vida em grupo não só acarreta benefícios, mas também em alguns custos. Os custos podem compreender diminuição da ingestão de alimentos e do ganho energético, aumento da transmissão de doenças e um possível aumento de agressões entre os indivíduos. Entre os benefícios estão a diminuição dos riscos de predação e a facilidade de acesso a parceiros sexuais (LOTT, 1991; EBENSPERGER, 2001; BORRIES et al., 2008). Neste contexto, a evolução da socialidade está relacionada à minimização de prováveis custos da vida em grupo e à maximização de seus benefícios.

Os sistemas sociais podem ser explicados através de três elementos fundamentais: a organização social, o sistema de acasalamento e a estrutura social (KAPPELER; van SCHAIK, 2002), que podem ser influenciados pela competição entre indivíduos e pelo mecanismo de seleção sexual (LOTT, 1991; POPE, 2000). A organização social descreve o tamanho e a composição sexual dos grupos; o sistema de acasalamento explica as interações entre os indivíduos do ponto de visto reprodutivo; e a estrutura social se refere aos padrões de interações sociais não reprodutivas entre os indivíduos e como os resultados destas relações interferem no sistema social (KAPPELER; van SCHAIK, 2002).

Segundo o modelo conceitual proposto por HINDE (1976) para explicar o comportamento social, a estrutura social de um grupo pode ser descrita a partir da natureza, qualidade e padrão das relações entre seus indivíduos. As relações entre os indivíduos, por sua vez, envolvem a interação entre eles levando em conta o conteúdo, qualidade e padrão das interações entre os indivíduos e ao longo do tempo. Por fim, as interações entre os indivíduos são o elemento básico da estrutura social de um grupo e são especificadas pelas atividades que dois indivíduos realizam juntos e como estes indivíduos estão realizando estas atividades, ou seja, são descritas pelo conteúdo e qualidade da interação entre dois indivíduos.

As interações entre os indivíduos de um grupo são contexto-dependentes, sendo influenciadas pela relação entre os indivíduos e podendo ter efeitos importantes sobre os padrões de acasalamento, cooperação e competição entre os indivíduos e, consequentemente, sobre sua aptidão (HINDE, 1976; CLUTTON-BROCK, 2009). Interações afiliativas entre os 
membros de um mesmo grupo podem ocorrer de forma preferencial entre alguns indivíduos, resultando no estabelecimento de vínculos sociais (LIM; YOUNG, 2006). Vínculo social (pair bond) ou amizade (friendship), que podem ser tratados como sinônimos (SILK, 2002; DUNBAR;SHULTZ, 2010; BRENT et al., 2014), pode ser estabelecido de acordo com a qualidade e os padrões de interação entre os indivíduos. Assim, podemos definir parceiros sociais (ou amigos) como indivíduos que interagem de forma afiliativa, não agressiva e não reprodutiva, mais frequentemente do que com outros indivíduos por períodos de tempo mais longos (CORDS, 1997, BRENT et al., 2014).

O vínculo entre indivíduos pode incluir passarem mais tempo em associação, forragearem juntos, compartilharem alimentos, maiores taxas de grooming, cooperação e até mesmo a formação de alianças contra outros indivíduos (BRENT et al., 2014). É possível que os mecanismos que regem o comportamento social e a formação de vínculos sejam os mesmo em diferentes taxa (BROAD; CURLEY; KEVERNE, 2006; DUNBAR, 2010; CHANG et al, 2013), o que aponta para uma história evolutiva mais antiga da socialidade. Vínculos sociais aparentemente tem sido úteis para diversas espécies e provavelmente são favorecidos pela seleção natural, estando provavelmente associado ao aumento do fitness do indivíduo, favorecendo sua sobrevivência e/ou sucesso reprodutivo (BRENT et al., 2014). Em mamíferos, são muitas as evidências que demonstram que o estabelecimento e a manutenção de vínculos aumentam o sucesso reprodutivo e a longevidade dos indivíduos (SEYFARTH; CHENEY, 2012) e trabalhos recentes tem corroborado esta relação entre a formação de vínculos sociais e o aumento do sucesso reprodutivo (CAMERON, SETSAAS, LINKLATER, 2009; SILK et al, 2010; BRENT et al., 2014).

As interações entre os parceiros reprodutivos estão implícitas na teoria da seleção sexual proposta por Darwin (1871), a qual reconhece duas formas de aptidão entre os indivíduos: a competição entre membros de um sexo para ter acesso a oportunidades de reprodução e a escolha pelos membros do outro sexo por parceiros do sexo oposto. Estas interações são extremamente diversas (PIZZANY; GARDNER, 2012). Em algumas espécies de mamíferos, os parceiros fazem grande parte de suas atividades juntos, como forragear e descansar. Em algumas espécies, machos e fêmeas permanecem juntos mesmo após a reprodução e o nascimento dos filhotes, mesmo quando não há cuidado paternal (KLEIMAN, 1974; BEISIEGEL, 1993) apontando para a formação de vínculo social entre os parceiros reprodutivos.

Machos e fêmeas variam muito no investimento reprodutivo, sendo este muito mais alto para as fêmeas, que aumentam seu sucesso reprodutivo através da seleção de parceiros de 
qualidade (BATEMAN, 1948; TRIVERS, 1972). Assim, diferente do que se pensava, as fêmeas possuem uma participação na formação de pares reprodutivos, avaliando e escolhendo um parceiro que lhe forneça recursos, sejam eles materiais ou genéticos, que aumentem seu sucesso reprodutivo (FISHER, 1930; VERNER, 1964; ORIONS, 1969; WHEATERHEAD; ROBERTSON, 1977). Comportamentos agressivos entre machos de mamíferos pelo acesso direto ou indireto às fêmeas (CLUTTON-BROCK et al., 1979; DAVIES; LUNDBERG, 1984; DREWS, 1996) muitas vezes levam a uma interpretação errada de que apenas os machos são os responsáveis pela formação de associações intersexuais e também pela seleção de parceiros reprodutivos (CLUTTON-BROCK; MCAULIFFE, 2009).

A estrutura social e as associações preferenciais de um grupo podem ser estudadas por meio da abordagem das Redes Sociais. O estudo das relações entre os indivíduos de um grupo pela abordagem das redes sociais pode revelar sutilezas da estrutura social decorrentes das estratégias individuais (CARTER et al., 2013). As análises de redes sociais baseiam-se em observações diretas dos indivíduos (LUSSEAU; NEWMAN, 2004) e analisados a partir de observações das interações entre díades, i.e. pares de animais, permitindo identificar a frequência e a força destas interações (KURVERS et al., 2013). A descrição estatística das redes permite que as diversas medidas comportamentais sejam comparadas, permitindo uma melhor compreensão das relações sociais dos indivíduos de uma espécie. As redes também permitem uma avaliação quantitativa da posição de um indivíduo em seu grupo social, indicando atribuição social e o número de parceiros de interação (LEHMANN; ROSS, 2011).

Outra vantagem das redes sociais é que elas podem representar qualquer tipo de interação entre indivíduos, como cooperação, competição, agressão e até mesmo a seleção de parceiros sociais e sexuais, permitindo ainda avaliar intensidade, direção e diversas outras variáveis acerca da relação entre os indivíduos estudados (KRAUSE et al., 2007). Além disto, as redes permitem identificar variações que podem ocorrer no grupo/população estudados, uma vez que as relações sociais e interações entre os animais não são fixas e as redes conseguem transmitir essas mudanças (WISNIEWSKI et al., 2012; HOBSON et al., 2013).

Evidências de que as parcerias sociais resultam em benefícios podem ser observadas em um grupo particular de roedores caviomorfos, as cobaias. As cobaias (Cavia porcellus Linnaeus, 1758) fazem parte do gênero Cavia Pallas, 1766, inserido na família Caviidae, pertencente à infraordem Hystricognathi (WOODS; KILPATRICK, 2005). Esta família é composta por roedores de porte médio, entre 200-750 mm, corpo robusto, cabeça grande, orelhas e membros curtos e cauda vestigial (ROOD, 1972; NOWAK, 1991). São animais de hábito crepuscular, com picos de forrageamento no início da manhã e no começo da noite, 
horários do dia com temperaturas mais amenas (ROOD, 1972; ASHER et al., 2004). A reprodução pode ocorrer durante o ano todo se as condições ambientais forem favoráveis (NOWAK, 1991). A gestação dura cerca de 60 dias e o filhote é precoce, com desenvolvimento avançado já ao nascimento (NOWAK, 1991).

Atualmente, são reconhecidas seis espécies no gênero Cavia: C. porcellus, C. tshudii, C. aperea, $C$. fulgida, $C$. magna e $C$. intermedia, sendo as quatro últimas espécies brasileiras e C. porcellus a única espécie domesticada do gênero (WOODS; KILPATRICK, 2005, DUNNUM; SALAZAR-BRAVO, 2010). Diferente do que se pensava anteriormente (CARTER, 1972; ROOD, 1972; KUNZL; SACHSER, 1999; TRILLMICH et al., 2004), C. porcellus não derivou-se de uma população de $C$. aperea. SPOTORNO e colaboradores (2004), a partir de comparações de sequências de citocromo b de cobaias (C. porcellus) com seis outras espécies de cavídeos, mostraram que, filogeneticamente, as cobaias estão mais próximas de $C$. tshudii do que de $C$. aperea.

A cobaia, que também é popularmente conhecida como porquinho-da-índia, provavelmente foi domesticada na região dos Andes de acordo com pinturas e múmias encontradas na região entre 1.000 e 500 a.C (WEIR, 1974). Os povos Incas domesticavam populações de preás selvagens, para utilizar como fonte de alimentos e também em cultos religiosos. A primeira descrição das cobaias foi feita por Oviedo em 1547, mesma época em que estes animais foram levados para a América Central e Europa após a invasão espanhola nos Andes, onde até hoje são utilizadas como animais de estimação e modelos de estudos científicos (CABRERA, 1953; WEIR, 1974).

Estudos comportamentais revelam que o repertório comportamental das cobaias é similar ao de espécies selvagens próximas, sem ausência ou adição de novos elementos, diferindo apenas na frequência em que certos comportamentos são exibidos: cobaias são menos agressivas e exibem significativamente mais comportamentos sócio-positivos KÜNZL; SACHSER, 1999). Observa-se também que o sistema de acasalamento é o mesmo de alguns preás, poliginia com guarda das parceiras, com formação de laços sociais estáveis entre os indivíduos (SACHSER, 1986; ADRIAN;SACHSER, 2011). Percebeu-se ainda uma grande plasticidade social nas cobaias: em alta densidade populacional as cobaias são capazes de subdividir o território em pequenas unidades, cada uma com seu macho alfa, que protege as fêmeas através de aliança com outros machos subordinados (SACHSER, 1986; SACHSER, 1998). A organização social das cobaias mostra uma grande tolerância entre coespecíficos e a habilidade em formar vínculos sociais de longa duração (SACHSER; RENNINGER, 1991). 
Dentro deste panorama, a proposta deste trabalho é investigar as associações entre os indivíduos adultos de uma colônia de cobaias (Cavia porcellus), por meio da abordagem das redes sociais. Além disto, queremos entender a participação das fêmeas na formação das associações intersexuais e, possivelmente, na seleção de parceiros utilizando um teste de escolha, em que a dominância e competição entre machos são minimizadas e, então, é possível observar manifestações de preferência da fêmea sem a interferência direta dos machos. 


\section{OBJETIVOS E HiPóteSES}

\section{Objetivos}

Observar a estrutura social de cobaias (Cavia porcellus) em colônia e descrever a formação de associações preferenciais intra- e intersexuais entre indivíduos adultos. Verificar, ainda, se em ambiente controlado, quando a competição entre machos e a dominância exercida sobre as fêmeas são minimizadas, as fêmeas demonstram preferência por um macho específico, indicando participação das fêmeas na formação das associações intersexuais e, possivelmente, na seleção de parceiros.

\section{Hipóteses}

I. Indivíduos adultos de cobaias formam associações preferenciais entre si, evidenciadas por índices de associação entre díades maiores do que a média do grupo.

II. Existe diferença entre as associações intra- e intersexuais, sendo as associações entre fêmeas mais fortes, i.e. índices de associação mais altos, do que associações entre os machos e entre fêmeas e machos.

III. Em relação aos diferentes machos apresentados no teste de escolha para as fêmeas, elas irão passar mais tempo com um macho específico e não necessariamente este macho será o mesmo para todas.

IV. Os resultados do teste de escolha em conjunto com os índices de associação das díades intersexuais demonstrarão a preferência das fêmeas por machos específicos, o que dará indícios da participação das fêmeas na formação das associações preferenciais intersexuais. 


\section{Metodologia}

\subsection{ANIMAIS EXPERIMENTAIS E MANUTENÇÃO}

As cobaias utilizadas como modelo experimental deste trabalho são de pelagem curta e colorida e padrão genético heterogêneo, adquiridas em diferentes criadores de três cidades do Estado de São Paulo (Ribeirão Preto, Cravinhos e São Carlos). Originalmente foi estabelecida uma colônia com seis animais adultos, três machos e três fêmeas. Com o passar do tempo, este número foi se alterando devido às mortes, nascimentos e inserções de novos animais (Tabela 3.1). Ao todo, foram utilizados 14 animais, sendo 4 machos e 10 fêmeas.

As cobaias foram mantidas em colônia em dois cercados diferentes (A e B), ambos na cidade de Ribeirão Preto. O cercado A abrigou os animais de setembro/2015 a abril/2016 (Situação 1). Possuía $12 \mathrm{~m}^{2}(3 \mathrm{mx} 4 \mathrm{~m})$, muro de alvenaria de $1 \mathrm{~m}$ de altura e mais $1 \mathrm{~m}$ de tela de alambrado completando a parede. Uma cobertura de alambrado e lona protegia os animais de chuva, sol e também da invasão de outros animais. O chão era de terra, coberto com feno e maravalha. Dentro do espaço, foram disponibilizadas caixas plásticas com cobertura em acrílico como abrigo para os animais. Entre abril/2016 e junho/2016 (Situação 2), os animais passaram a habitar o cercado $B$, um espaço de $18 m^{2}(6 m \times 3 m)$ mais construção anexa a este espaço, com aproximadamente $2 \mathrm{~m}^{2}$, que lhes servia de abrigo na chuva, e também caixas plásticas com cobertura em acrílico. O chão também era de terra, coberto com feno e maravalha.

Os animais receberam água e comida ad libitum (Ração Nuvilab para animais de laboratório; Nuvital Nutrientes S/A, Brasil) e complementos alimentares vegetais esporadicamente. Semanalmente os animais eram pesados e era feita uma triagem de seu estado de saúde, na qual verificava-se se haviam machucados e perda excessiva de peso (perdas de mais de 10\% do peso de uma semana para outra pode indicar sinais de doença). Os cuidados com os animais seguem as normativas do CONCEA (autorização do comitê de ética: CEUA-IP/USP $n^{\circ}$ 6346080515) e as recomendações da Sociedade Americana de Mamologistas para manutenção de mamíferos cativos (SIKES;GANNON, 2011). 
Tabela 3.1. Identificação dos animais que compuseram a colônia ao longo da pesquisa, com nome, sexo e idade, e indicação da data em que cada indivíduo nasceu (para os jovens) ou que foi inserido (para os adultos) na colônia.

\begin{tabular}{lccccc}
\hline Identificação & Nome & Abreviação $^{*}$ & Sexo & Idade & Data de entrada \\
\hline CP001 & Chocolate & Choc & Macho & Adulto & $01 / 09 / 2015$ \\
CP006 & George & Geo & Macho & Adulto & $01 / 09 / 2015$ \\
CP007 & Latrel & Lat & Macho & Adulto & $01 / 09 / 2015$ \\
CP009 & Wiggly & Wig & Fêmea & Adulto & $01 / 09 / 2015$ \\
CP010 & Luzi & Luz & Fêmea & Adulto & $01 / 09 / 2015$ \\
CP022 & Poá** & Poa & Fêmea & Adulto & $01 / 09 / 2015$ \\
CP033 & Brisa & Bri & Fêmea & Adulto & $05 / 01 / 2016$ \\
CP034 & Fúria da Noite & Fur & Fêmea & Adulto & $05 / 01 / 2016$ \\
CP035 & Tempestade & Tem & Fêmea & Adulto & $05 / 01 / 2016$ \\
CP036 & Marin & Mar & Fêmea & Adulto & $21 / 02 / 2016$ \\
CP038 & Lady Gaga & Gag & Fêmea & Adulto & $05 / 01 / 2016$ \\
CP043 & Tantor & Tan & Macho & Jovem & $21 / 12 / 2015$ \\
CP053 & Maya & May & Fêmea & Jovem & $05 / 01 / 2016$ \\
CP056 & Raquel & Raq & Fêmea & Jovem & $05 / 01 / 2016$ \\
\hline
\end{tabular}

* Estas abreviações aparecerão ao longo do texto em tabelas e figuras como representação dos indivíduos.

** Poá não está presente nas coletas de dados a partir de janeiro/2016, pois morreu em 11/01/2016.

\subsection{FORMAÇÃO DE ASSOCIAÇÕES EM COLÔNIA}

\section{Coleta de dados}

Para investigarmos como os animais se associam quando vivem em colônias foi preciso registrar as atividades diárias dos animais. Os animais foram filmados na colônia em dois períodos diferentes (Situação 1 - set/2015 a nov/2015; Situação 2 - mar/2016 a jun/2016), cada um deles referente à formação da colônia em um dos cercados já descritos (ver tópico 3.1). Mais detalhes sobre as diferentes composições da colônia podem ser vistos na seção 3.1 Animais Experimentais e Manutenção. Em ambos os períodos, os animais foram filmados duas vezes por semana, em dias alternados, por 30 minutos (Situação 1) e 1 hora (Situação 2).

Nos dois momentos de coleta de dados (Situação 1 e Situação 2), as filmagens ocorreram no período claro do dia, entre $8 \mathrm{~h}$ e $18 \mathrm{~h}$. Não foram feitos registros no período escuro do dia devido à dificuldade de identificação dos animais na falta de claridade. Porém, devido ao ciclo de atividade ultradiano dos animais, com picos de atividade a cada duas horas (ROOD, 1972; ASHER et al., 2004), podemos considerar que a falta de registros no período 
noturno não implicou em perda de informações. Além disto, os maiores picos de atividades da espécie ocorrem no período crepuscular (início da manhã e final da tarde), o qual foi amostrado. Os dias da semana em que as filmagens ocorreram eram praticamente fixos, de acordo com a disponibilidade do pesquisador, mas os horários em que as filmagens ocorreriam foram sorteados. Foram utilizadas simultaneamente duas câmeras filmadoras (Sony Handcam HDR-CX220 e Sony Handcam HDR-MV1; Japão) e dois tripés (Vector WT3770) para que toda a extensão do cercado fosse coberta.

\section{Análise de Dados}

Para o registro das associações entre os animais os vídeos gravados na colônia foram analisados por meio do método de escaneamento com registros instantâneos com intervalos de 3 minutos. A unidade utilizada nas análises de associação foram as díades, i.e., agrupamento de quaisquer dois indivíduos. Assim, foram registradas quais díades estavam em associação em cada scan. Foram considerados em associação animais que estivessem próximos fisicamente (até dois corpos de distância) (Figura 3.1) e que apresentassem comportamentos sócio-positivos. Associações entre animais que apresentavam comportamentos agonísticos no momento do scan não foram contabilizadas. Para determinar comportamentos sócio-positivos e agonísticos foram utilizados os etogramas de Cavia descritos por ROOD (1972), KUNZL; SACHSER (1999), MONTICELLI (2005), FURNARI (2006), FURNARI (2011) e SANTOS (2013).

Os dados obtidos através da análise dos vídeos foram transcritos para planilhas de Excel (Microsoft, USA) nas quais em uma coluna foram anotados os dias e os horários dos scans e em outra coluna foi registrada a identificação dos indivíduos em associação. Foram montadas duas planilhas, uma para cada formação da colônia (Situação 1 e Situação 2). Todos os cálculos realizados nesta fase foram feitos e serão apresentados seguindo esta divisão. Os arquivos de Excel foram inseridos no SOCPROG (WHITEHEAD, 2009), software utilizado para a realização de todos os cálculos apresentados nesta seção.

\section{- Análise das associações}

A associação entre um par de indivíduos foi estimada como a proporção de tempo em que foram observados juntos, mediante Índice de Associação (IA). O índice de associação varia entre 0 , quando a díade nunca foi observada em associação, e 1, quando a díade foi vista 
(a)

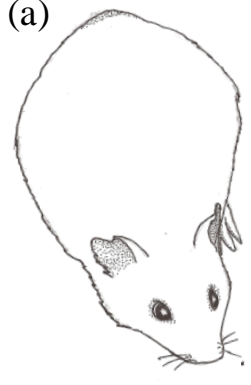

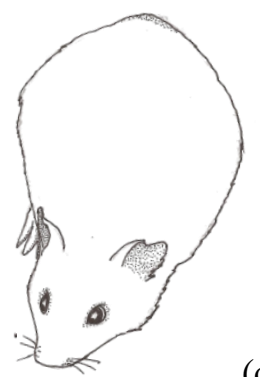

(c)

(b)
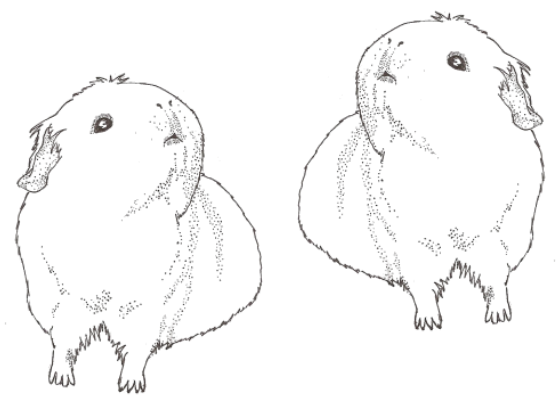

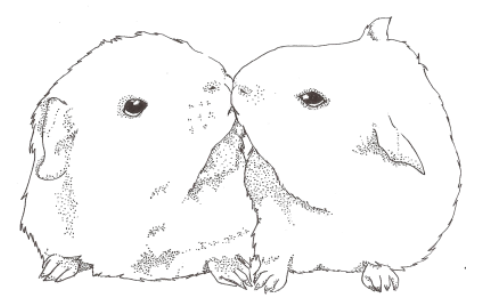

Figura 3.1. Exemplos de animais em proximidade espacial considerada como associação para o cálculo do Índice de Associação. (a) díade forrageando junta; (b) díade explorando o ambiente; (c) contato focinho-focinho entre a díade. Desenhos de Juliana Takata com base nas filmagens da colônia.

em associação todas as vezes. Para este trabalho foi escolhido o Índice de Razão Simples (simple ratio index, CAIRNS; SCHWAGER, 1987), utilizando a opção Date como período amostral no software SOCPROG. Este índice é apropriado para estudos em que todos os indivíduos podem ser identificados, possibilitando a identificação de todas as suas associações e, portanto, descartando a possibilidade de viés na análise dos dados. Isto é possível em grupos pequenos e quando se consegue registras as associações entre os animais, como é o caso deste trabalho.

$\mathrm{O}$ índice de associação de Razão Simples é calculado por meio da fórmula $\mathrm{IA}_{\mathrm{XY}}=$ $\mathrm{a} / \mathrm{a}+\mathrm{b}+\mathrm{c}$ onde $a$ representa o número de registros em que os indivíduos $\mathrm{X}$ e $\mathrm{Y}$ foram observados concomitantemente, $b$ o número de registros em que apenas $\mathrm{X}$ foi visto e $c \mathrm{o}$ número de registros em que apenas Y aparece (GINSBERG; YOUNG, 1992). Os índices de todas as díades foram organizados em uma matriz de associação.

\section{- Teste de preferência e/ou evitação entre os indivíduos}

O teste de preferencia e/ou evitação (Prefered/Avoidance Test) realizado pelo SOCPROG testa se os indivíduos do grupo se associam de forma aleatória ou não (BEJDER; FLETCHER; BRAGER, 1998). A hipótese nula seria que os indivíduos se associam com a mesma probabilidade com todos os outros indivíduos. Para testar esta hipótese, o programa 
compara os dados da matriz de associação com várias matrizes criadas em um teste de permutação. Para os dados deste trabalho, foram utilizadas 10.000 permutações para a Situação 1 e 100.000 permutações para a Situação 2. Para escolher o número de permutações, o mesmo foi aumentado até que o valor de $p$ se estabilizasse. Tanto na Situação 1 quanto na Situação 2 foi utilizado o método de permutação "permut all groups" com 1000 flips por permutação. Este método é indicado para estudo em que os indivíduos tenham alta probabilidade de estarem presentes na área de estudo em cada período amostral, como em estudos com grupos pequenos de animais cativos, como é o caso deste trabalho. A preferência ou evitação entre indivíduos, neste caso, é dada por um valor de desvio padrão (SD) dos dados reais significativamente maior que o dos dados permutados.

\section{- Definição das associações preferenciais}

A associação preferencial de uma díade foi definida pelo compartilhamento preferencial de um mesmo espaço físico por indivíduos específicos mais frequentemente do que se esperaria ao acaso (DURREL et al., 2004). As associações preferenciais foram neste trabalho definidas a partir da comparação do IA de uma díade com o IA médio do grupo: sempre que o IA da díade fosse maior que o da média do grupo esta associação era considerada como preferencial.

Além disto, também foi testado se havia diferença entre as associações intra e intersexuais por meio do Teste de Mantel (SCHNELL et al., 1985) com 1000 permutações. A hipótese nula do teste é que não existe diferença entre as classes testadas. Os resultados foram expressos pelos valores de $t$, de $p$ e de correlação entre matrizes. Quando p apresenta valores entre 0,025 e 0,975 a hipótese nula não é rejeitada. Quando as associações intra-classes são mais fortes, $p>0,975$ e os valores de $t$ e de correlação de matrizes são positivos. Se as associações entre classes forem mais fortes, $p<0,025$ e os valores de $t$ e de correlação de matrizes são negativos (WHITEHEAD, 2009).

Como o objetivo deste trabalho foi investigar a formação de associações intersexuais entre adultos visando correlacionar as preferências sociais com a seleção de parceiros, foram desconsideradas, seguindo a literatura (RAMOS-FERNANDEZ et al., 2009; SUSCKE, 2014), as associações entre mães e filhotes. Consequentemente, para nenhuma medida envolvendo os índices de associação as díades mãe-filhote foram consideradas. 


\section{- Análise de Redes Sociais}

O método de análise de redes sociais (Social Network Analysis) permite descrever, quantificar e comparar estatisticamente as relações sociais entre indivíduos de um grupo (CROFT; JAMES; KRAUSE, 2008). Duas métricas de rede foram calculadas para avaliar a centralidade do indivíduo dentro do grupo a partir da matriz de associação, segundo WHITEHEAD (2009):

- Força (strenght): quantifica a sociabilidade de cada indivíduo, a partir da soma de todos os IA de um indivíduo com cada membro do grupo. Altos valores de força indicam que o indivíduo possui associações fortes com os outros indivíduos e/ou que possui um grande número de associações.

- Centralidade do Autovetor (eigenvector centrality): estima a importância de cada indivíduo na rede através de um cálculo que envolve a soma dos IA do indivíduo com o autovetor de maior autovalor da matriz de associação. Indivíduos que apresentam altos valores de Centralidade do Autovetor apresentam um papel central na rede, por apresentarem associações fortes com muitos indivíduos ou por se associar com indivíduos centrais.

A representação gráfica das associações espaciais foi realizada por meio de redes desenhadas no software NODEXL (2014). As redes sociais são constituídas por pontos interligados (nós) que representam os indivíduos e por linhas (arestas) que demonstram as associações entre os indivíduos. Quanto mais espessas as linhas, mais fortes são estas associações (i.e., maiores são os valores de IA) e quanto maiores os nós maiores os valores de centralidade do autovetor daquele indivíduo.

\subsection{TESTE DE PREFERÊNCIA}

Os procedimentos experimentais e o aparato utilizado no teste de preferência foram modificados a partir dos modelos utilizados por WEBSTER; WILLIAMS; DEWSBURRY (1982) e MANAF; OLIVEIRA (2009). Para a realização dos testes escolhemos entre os animais que compunham a colônia experimental há mais tempo três machos (Latrel, Chocolate e George) e cinco fêmeas (Wiggly, Luzi, Lady Gaga, Marin e Fúria da Noite). Maiores informações sobre os animais e detalhes sobre a manutenção dos mesmos se encontram na seção 3.1 Animais Experimentais. 
Como este teste visa entender as associações sociais não utilizamos fêmeas no período receptivo. Como nas espécies do gênero Cavia machos e fêmeas permanecem juntos após a cópula formando um grupo estável em forma de harém e há evidências de que os machos cortejam as fêmeas também fora do estro (WEIR, 1974), acreditamos que a fêmea escolha se associar a um macho antes mesmo da cópula e que mantenha esta associação após seu período receptivo.

A arena utilizada para testar a preferência das fêmeas foi instalada em uma das salas de experimentação de nosso biotério. O espaço da arena media $1,4 \times 1,15 \mathrm{~m}$ e era dividido em três compartimentos. Nos compartimentos das extremidades eram colocados os machos, limitados ao seu espaço através do uso de coleira peitoral e guia conectada a um varal que permitia a movimentação do animal, mas não o deixava sair de seu compartimento. $O$ compartimento do meio ficava vazio. As fêmeas eram colocadas inicialmente no espaço vazio e aberturas nas divisórias dos compartimentos permitiam à fêmea transitar livremente (Figura 3.2). Em todos os compartimentos foram disponibilizadas ração e água ad libitum.

Cada sessão durou 2 horas e foi filmada através do sistema de monitoramento (câmeras de segurança conectadas a um DVR que faz as gravações e as armazena em um HD externo) existente na sala de experimentação. Ao final de cada sessão, a maravalha que cobria o chão era trocada e a arena era limpa com álcool $42 \%$ para que possíveis "rastros" deixados pela fêmea anterior não atrapalhassem a decisão da fêmea que estava sendo testada.

Os machos foram testados aos pares, em três combinações diferentes (Latrel x Chocolate, Latrel x George e Chocolate x George). O compartimento que cada macho ocuparia em cada um dos testes foi aleatorizado para garantir que a decisão da fêmea não fosse enviesada pelo espaço físico que o macho ocupava. Foram realizados três testes por dia e um intervalo de pelo menos 48 horas era dado entre cada conjunto de testes. As fêmeas foram expostas aos três pares de machos, em dias diferentes, e cada sessão foi repetida três vezes para cada par de machos. Uma fêmea nunca foi testada mais de uma vez no mesmo dia. No total foram realizados 45 testes de preferência. 


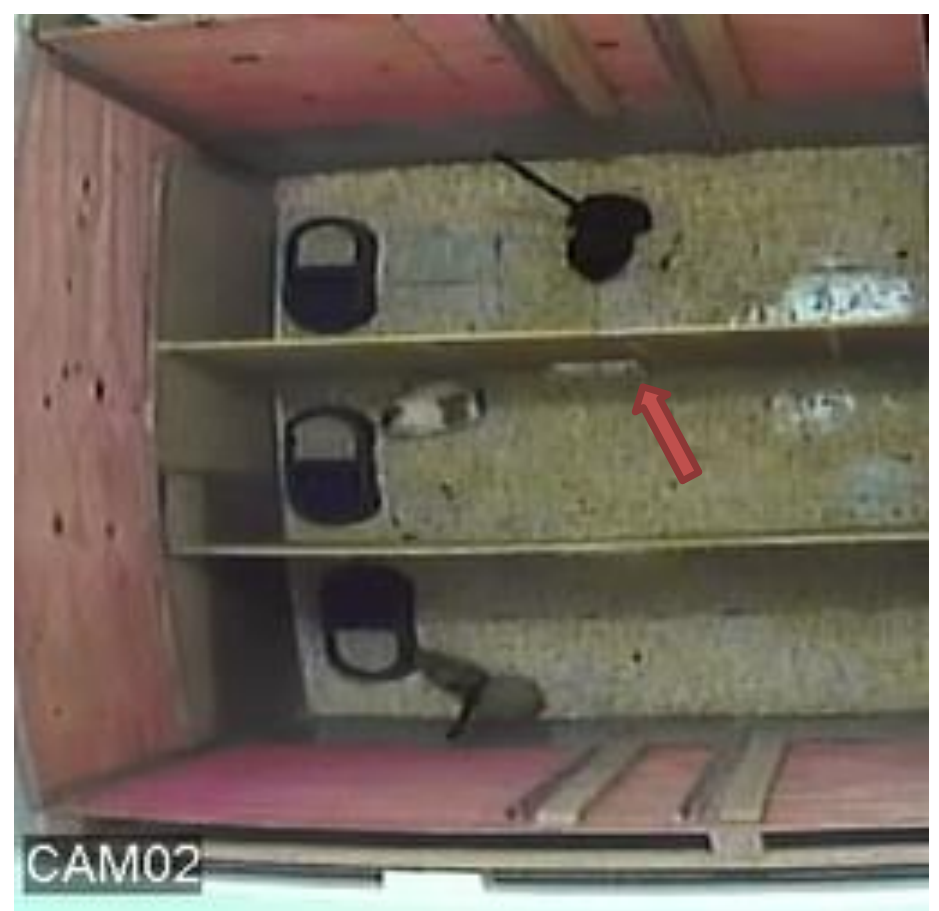

Figura 3.2. Imagem do cercado utilizado para o teste de escolha, retirada de uma das filmagens feitas durantes os testes. Nos cercados das extremidades encontram-se os machos (Latrel - acima, George - abaixo), presos por coleiras, enquanto a fêmea (Marin - centro) pode se locomover livremente por todos os compartimentos através de aberturas nas divisórias, indicada na imagem pela seta vermelha.

\section{Análise dos Dados}

A partir dos vídeos feitos durante as sessões, contamos quanto tempo a fêmea passava no compartimento de cada macho durante cada uma das sessões e também o tempo em que ela ficava no compartimento vazio. A partir destes dados calculamos a porcentagem de tempo em que a fêmea permaneceu em cada um dos compartimentos em cada sessão.

O tempo em que as fêmeas, de forma geral, passaram em cada compartimento foi comparado de duas formas: (1) o tempo que as fêmeas permaneceram sozinhas no compartimento central em relação ao tempo total que as fêmeas permaneceram com os machos, em qualquer dos compartimentos, nas sessões e (2) para cada um dos três pares, o tempo em que as fêmeas permaneceram com cada um dos machos.

Analisamos a distribuição dos dados com o teste de Shapiro-Wilk e a homocedasticidade pelo teste de Levene, utilizando o software SPSS 22 (IBM®, USA). Como os dados não atenderam as premissas necessárias para a aplicação de testes paramétricos, as comparações foram realizadas através dos testes de Mann-Whitney (1) e 
Kruskal-Wallis seguido de teste post-hoc Student-Newman-Keuls (2), ambos com nível de significância $5 \%$.

Além disto, analisamos também os tempos individuais de cada fêmea dentro dos compartimentos dos machos para cada um dos três pares para investigarmos a preferência de cada uma das fêmeas e se estes resultados individuais estariam em concordância com os resultados gerais para todas as fêmeas. Utilizamos também o teste de Shapiro-Wilk e a homocedasticidade pelo teste de Levene, por meio do software SPSS 22 (IBM®, USA). Neste caso os dados atenderam as premissas para a aplicação de testes paramétricos, então as comparações foram feitas através do teste $t$ de Student. 


\section{RESUltados}

\subsection{FORMAÇÃO DE ASSOCIAÇÕES PREFERENCIAIS EM COLÔNIA}

Os testes de Preferência e/ou Evitação mostraram que nas duas variações da colônia (Situação 1 e Situação 2) as associações foram diferentes do esperado ao acaso. Na Tabela 4.1 é possível observar que os valores de desvio padrão (SD) foram significativamente maiores para os índices de associações reais em relação aos dados permutados.

Tabela 4.1. Resultado do teste de preferência e/ou evitação para as associações das cobaias (Cavia porcellus) nas duas variações da colônia. Valores reais de desvio padrão (SD) maiores que os randômicos e $p<0,05$ rejeitam a hipótese nula de que as associações entre os indivíduos são aleatórias na Situação 1 e na Situação 2.

\begin{tabular}{cccc}
\hline & & Situação 1 & Situação 2 \\
\hline N permutações & 10.000 & 100.000 \\
N flips/permutação & 1.000 & 1.000 \\
& & & \\
Desvio Padrão & Real & 0,162 & 0,1704 \\
(SD) & Randômico & 0,138 & 0,156 \\
& $p$ value & 0,01 & 0,002 \\
\hline
\end{tabular}

Os valores de IA de cada díade foram comparados ao IA médio nas duas situações para a determinação das associações preferenciais (Tabela 4.2). O Teste de Mantel mostrou que na Situação 1 não houve diferença entre as associações intra- e intersexuais. Já na Situação 2, em que o número de indivíduos na colônia era maior, há diferença na associação entre os sexos, sendo as associações entre as fêmeas mais fortes do que entre os machos e entre fêmeas e machos (Tabela 4.3). 
Tabela 4.2. Valores dos Índices de Associação (IA) das díades que apresentam associação preferencial $\left(\mathrm{IA}_{\text {díde }}>\mathrm{IA}_{\text {médio }}\right.$ ) entre cobaias (Cavia porcellus) adultas nas duas variações da colônia. * representa as associações intersexuais.

\begin{tabular}{|c|c|c|c|}
\hline \multicolumn{2}{|c|}{$\begin{array}{c}\text { Situação } 1 \\
\left(\mathrm{IA}_{\text {médio }}=0,32\right)\end{array}$} & \multicolumn{2}{|c|}{$\begin{array}{c}\text { Situação } 2 \\
\left(\mathrm{IA}_{\text {médio }}=0,42\right)\end{array}$} \\
\hline Díade & IA & Díade & IA \\
\hline Wig-Lat* & 0,6 & Bris-Wig & 0,8 \\
\hline Luz - Lat* & 0,6 & Gag-Geo* & 0,8 \\
\hline Luz-Geo* & 0,5 & Luz-Gag & 0,7 \\
\hline Wig-Choc* & 0,5 & Tem-Gag & 0,7 \\
\hline Wig-Poa & 0,4 & Mar-Gag & 0,7 \\
\hline \multirow[t]{30}{*}{ Luz-Poa } & 0,4 & Gag-Lat* & 0,7 \\
\hline & & Gag-Wig & 0,7 \\
\hline & & Lat-Wig* & 0,7 \\
\hline & & Choc-Wig* & 0,6 \\
\hline & & Luz-Tem & 0,6 \\
\hline & & Luz-Geo* & 0,6 \\
\hline & & Bri-Mar & 0,6 \\
\hline & & Bris-Geo* & 0,6 \\
\hline & & Fur-Lat* & 0,6 \\
\hline & & Tem-Mar & 0,6 \\
\hline & & Tem-Geo* & 0,6 \\
\hline & & Tem-Wig & 0,6 \\
\hline & & Mar-Lat* & 0,6 \\
\hline & & Raq-Wig & 0,6 \\
\hline & & Geo-Wig* & 0,6 \\
\hline & & Choc-Mar* & 0,5 \\
\hline & & Luz-Fur & 0,5 \\
\hline & & Luz-May & 0,5 \\
\hline & & Luz-Lat* & 0,5 \\
\hline & & Bri-Fur & 0,5 \\
\hline & & Bri-Gag & 0,5 \\
\hline & & Bri-Raq & 0,5 \\
\hline & & Fur-Raq & 0,5 \\
\hline & & Tem-Tan* & 0,5 \\
\hline & & Tem-May & 0,5 \\
\hline & & Tem-Lat* & 0,5 \\
\hline & & Gag-Tan* & 0,5 \\
\hline & & Tan-Raq* & 0,5 \\
\hline & & May-Lat* & 0,5 \\
\hline & & May-Wig & 0,5 \\
\hline
\end{tabular}


Tabela 4.3. Média e desvio padrão, entre parênteses, dos Índices de Associação intra e inter classes e resultado do Teste de Mantel para comparação das diferenças entre associações intra- e intersexuais entre cobaias (Cavia porcellus) adultas nas duas variações da colônia. F-F representa a associação entre fêmeas, M-M representa a associação entre machos e F-M representa a associação entre fêmeas e machos. Valores positivos para $t$ e correlação de matrizes e $p$ próximo a 1 rejeitam a hipótese nula do teste de que não há diferença entre as associações intra e inter classes.

\begin{tabular}{lcc}
\hline & Situação 1 & Situação 2 \\
\hline F-F & $0,33(0,05)$ & $0,45(0,07)$ \\
M-M & $0,17(0,03)$ & $0,25(0,08)$ \\
F-M & $0,37(0,10)$ & $0,42(0,11)$ \\
$t$ & $-1,292$ & 0,094 \\
$p$ & 0,1962 & 0,9751 \\
$\begin{array}{l}\text { correlação } \\
\text { de matrizes }\end{array}$ & $-0,3572$ & 0,0125 \\
\hline
\end{tabular}

Nas figuras 4.1 e 4.2 temos a representação das relações dos indivíduos na colônia nas duas variações. Para uma melhor visualização, as associações consideradas preferenciais, i.e. IAs maiores que o IA médio, estão em destaque.

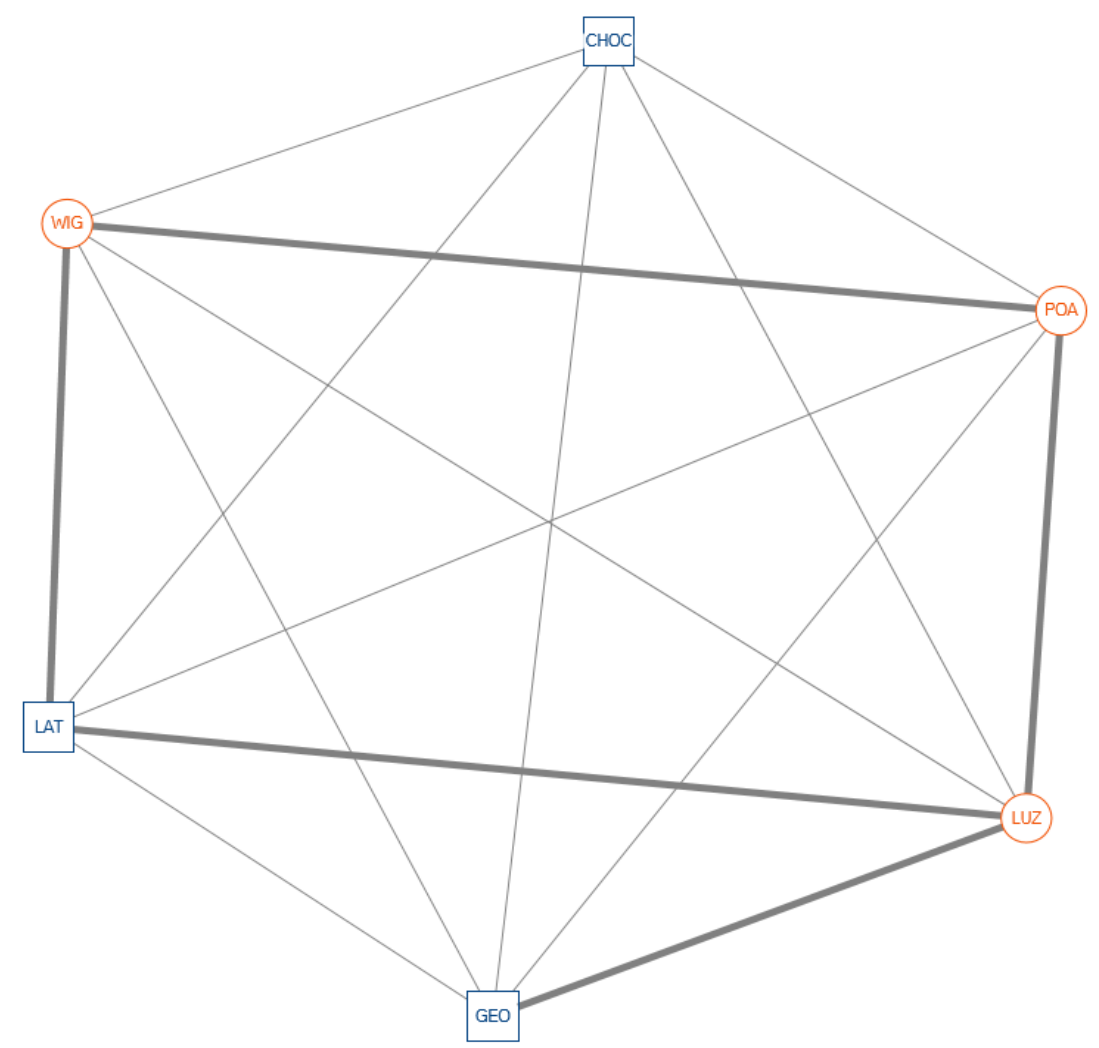

Figura 4.1. Rede Social entre as cobaias em colônia na Situação 1. Círculos representam as fêmeas e quadrados, os machos. As linhas mais espessas representam as associações preferenciais (IAdíade>IAmédio). 


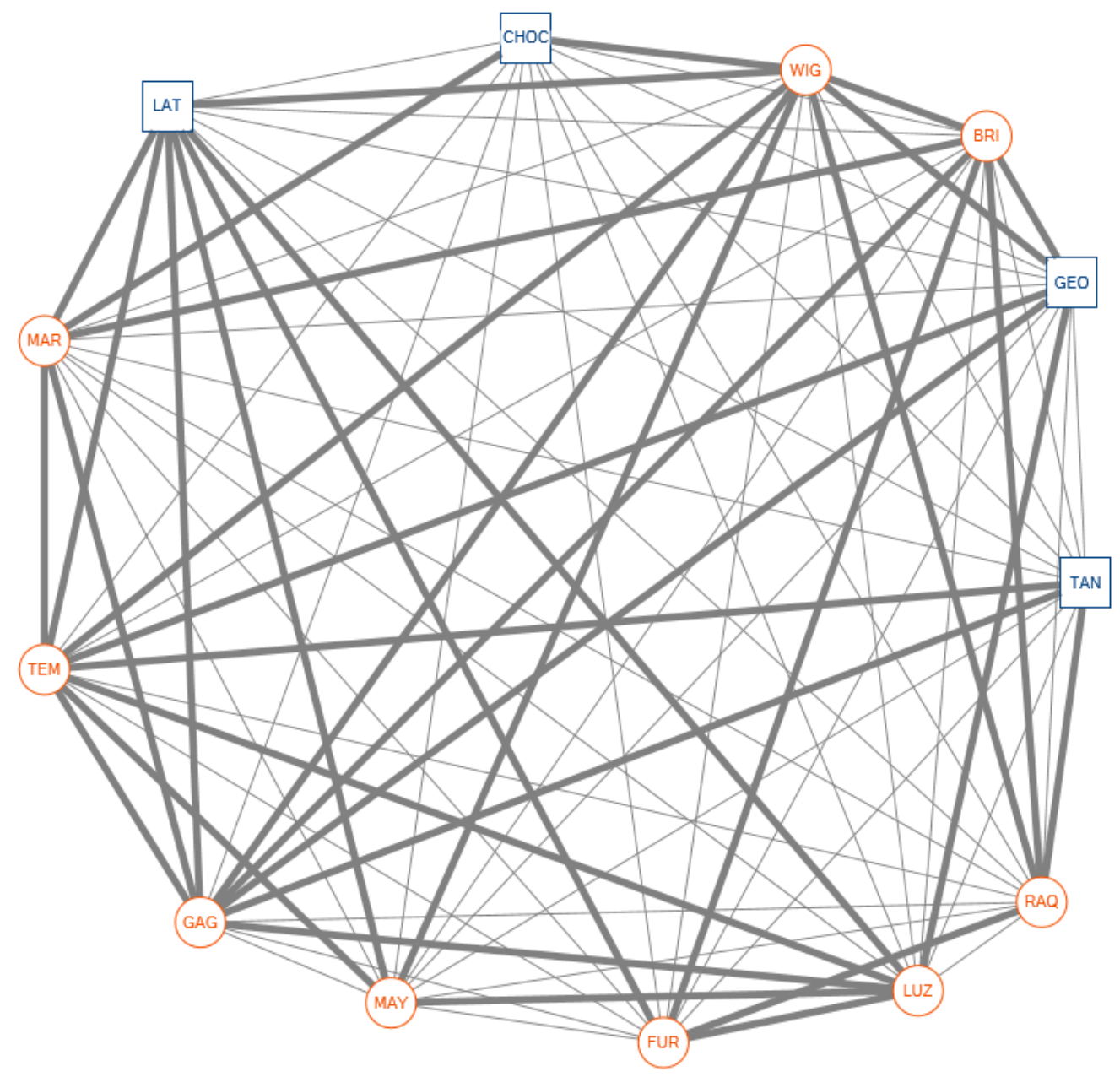

Figura 4.2. Rede Social entre as cobaias em colônia na Situação 2. Círculos representam as fêmeas e quadrados, os machos. As linhas mais espessas representam as associações preferenciais (IAdíade>IAmédio).

A análise de redes sociais mostrou que os indivíduos com os mais altos valores de força são fêmeas (Figuras 4.3). Entre os machos, Latrel é o que possui maiores valores de força e centralidade, o que indica que é o macho que se associa com a maior parte dos indivíduos, preferencialmente com as fêmeas como observado nas Figuras 4.1 e 4.2. Na Situação Experimental 2 é possível observar que o indivíduos centrais da colônia, ou seja, que possuem maiores valores de Força e Centralidade do auto-vetor são, entre as fêmeas, Lady Gaga e Wiggly e, entre os machos, Latrel e George, nesta ordem. 
(a)

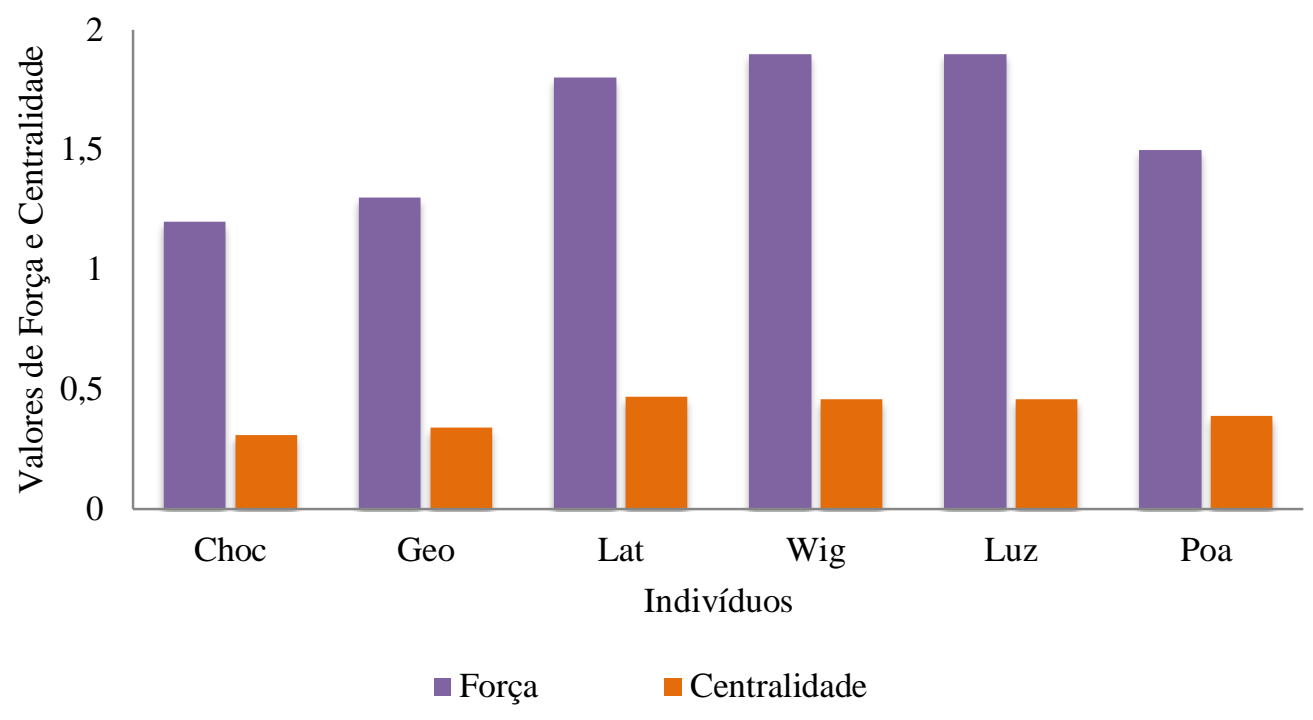

(b)

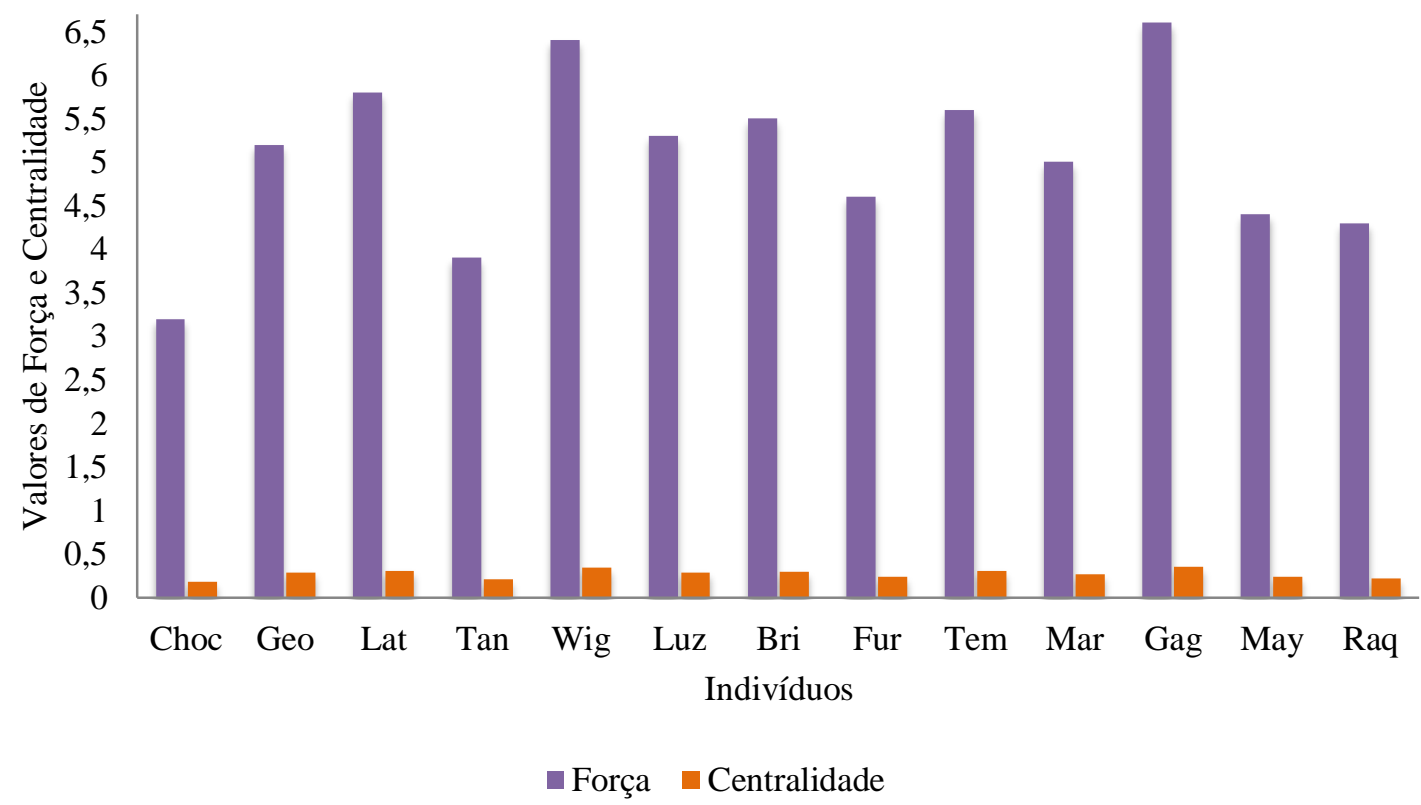

Figura 4.3. Resultado das Análises de Redes Sociais. Valores de Força e Centralidade do Autovetor para as cobaias (Cavia porcellus) adultas nas duas variações da colônia: Situação 1 (a) e Situação 2 (b).

Em complemento às métricas de Redes Sociais e as redes desenhadas, a Figura 4.4 permite uma melhor visualização do número de associações preferenciais que cada um dos indivíduos da colônia estabelece. Em concordância com os resultados da Análise de Redes Sociais, Lady Gaga, Wiggly, Latrel e George são os indivíduos que estabeleceram o maior número de associações preferenciais dentro da colônia. 
(a)

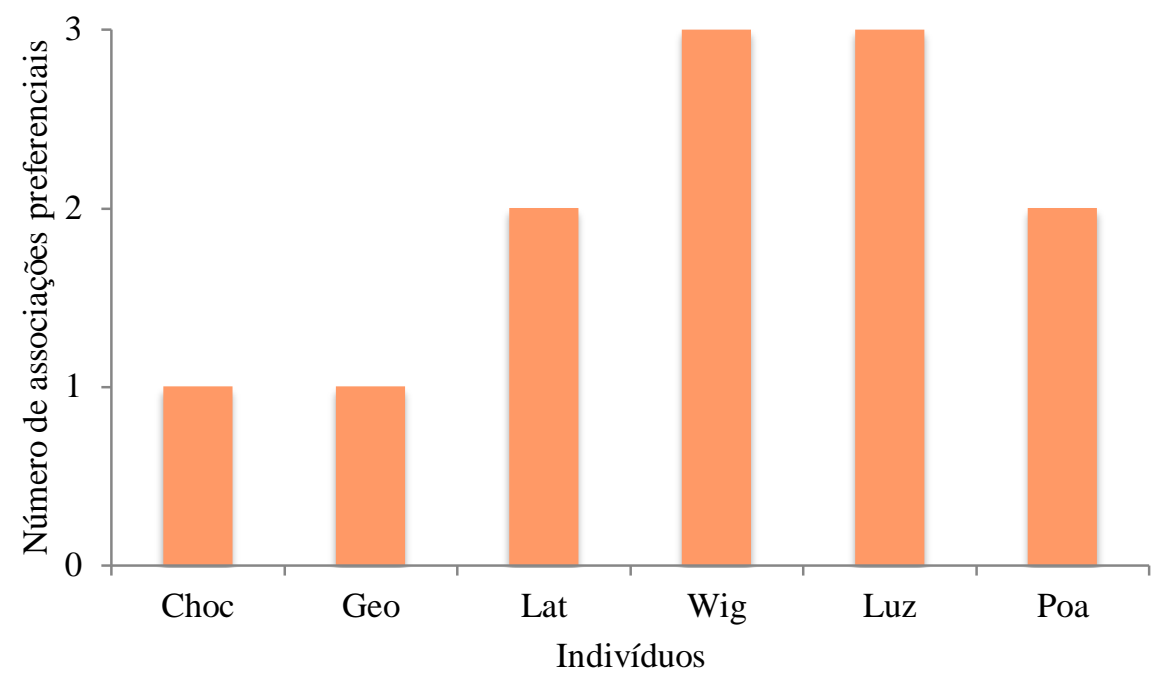

(b)

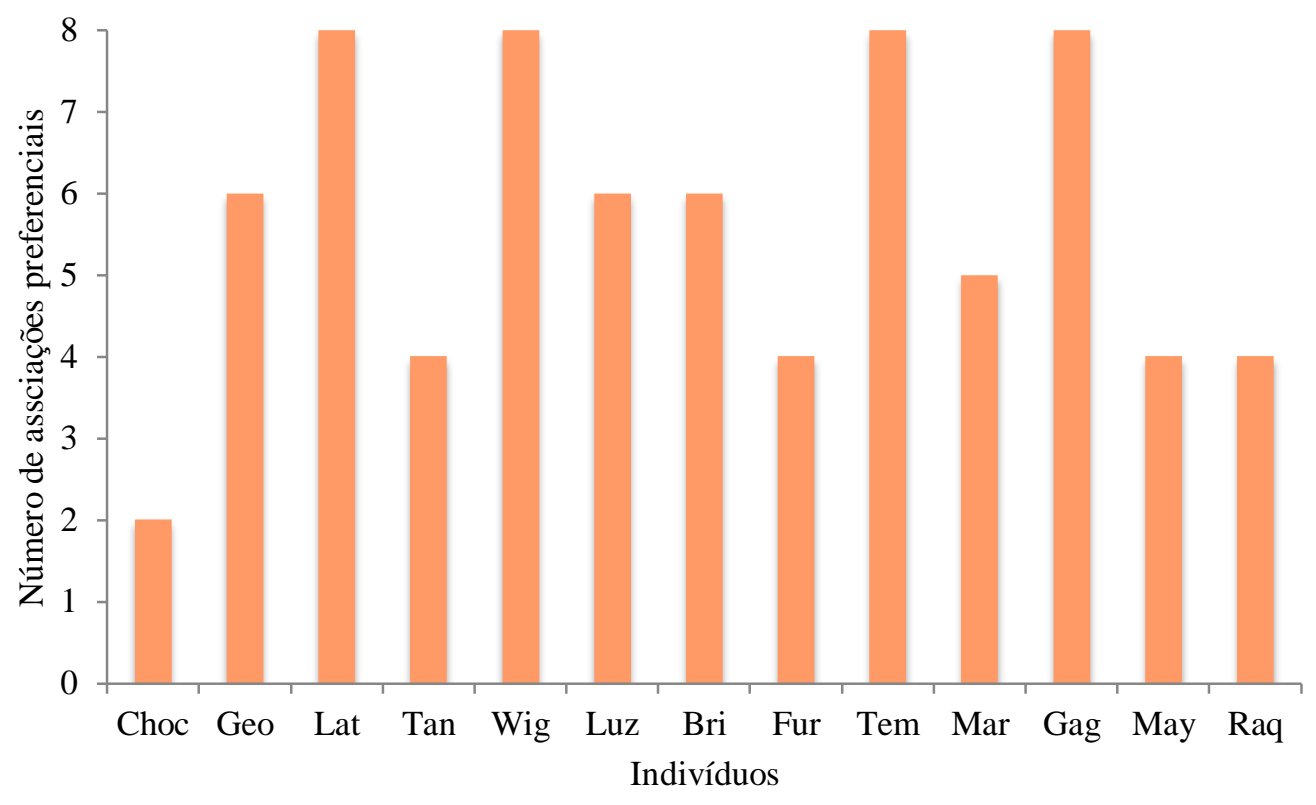

Figura 4.4. Quantidade de associações preferenciais formadas por cada cobaia (Cavia porcellus) adultas na colônia nas duas variações da colônia: Situação 1 (a) e Situação 2 (b).

A partir das análises apresentadas anteriormente, é possível perceber que há pequenos agrupamentos preferenciais entre os indivíduos, que foram semelhantes em ambas as Situações Experimentais. As fêmeas se organizam em díades ou trios nos quais os indivíduos possuem associações mais fortes entre si do que com as outras fêmeas. Entre os machos, observa-se que Latrel é o macho que se associa preferencialmente à maioria das fêmeas em ambas as situações. O segundo macho com os IAs mais altos com as fêmeas é o George. Os valores de IA (entre Latrel e George e de cada indivíduo com as fêmeas), força e centralidade 
destes dois machos dão indícios de que Latrel seja o macho dominante da colônia e que George é um macho subordinado associado ao Latrel. Chocolate e Tantor, devido aos seus baixos valores de IA, força e centralidade, seriam, então os machos satélite da colônia.

A Figura 4.5 representa a possível estrutura social das cobaias estudadas neste trabalho com base nos valores de IA, força e centralidade calculados para cada indivíduo. O posicionamento de cada indivíduo indica os valores de centralidade, ou seja, quanto mais ao centro o indivíduo maior o valor de centralidade do autovetor atribuído a ele. O tamanho dos símbolos que representam os indivíduos (quadrados para machos e círculos para fêmeas) representam seus valores de força, ou seja, quanto maior o símbolo maior o valor de força do indivíduo. Por fim, os valores de IA são representados pelas linhas que ligam os indivíduos e quanto mais espessa a linha, maior o valor de IA daquela associação.

Esta é uma forma alternativa de representar a estrutura social da colônia de cobaias estudada. Não foram representadas aqui todas as associações entre os indivíduos, mas sim aquelas consideradas importantes para a visualização das pequenas agregações preferenciais entre algumas fêmeas e a relação dos machos com as fêmeas. 


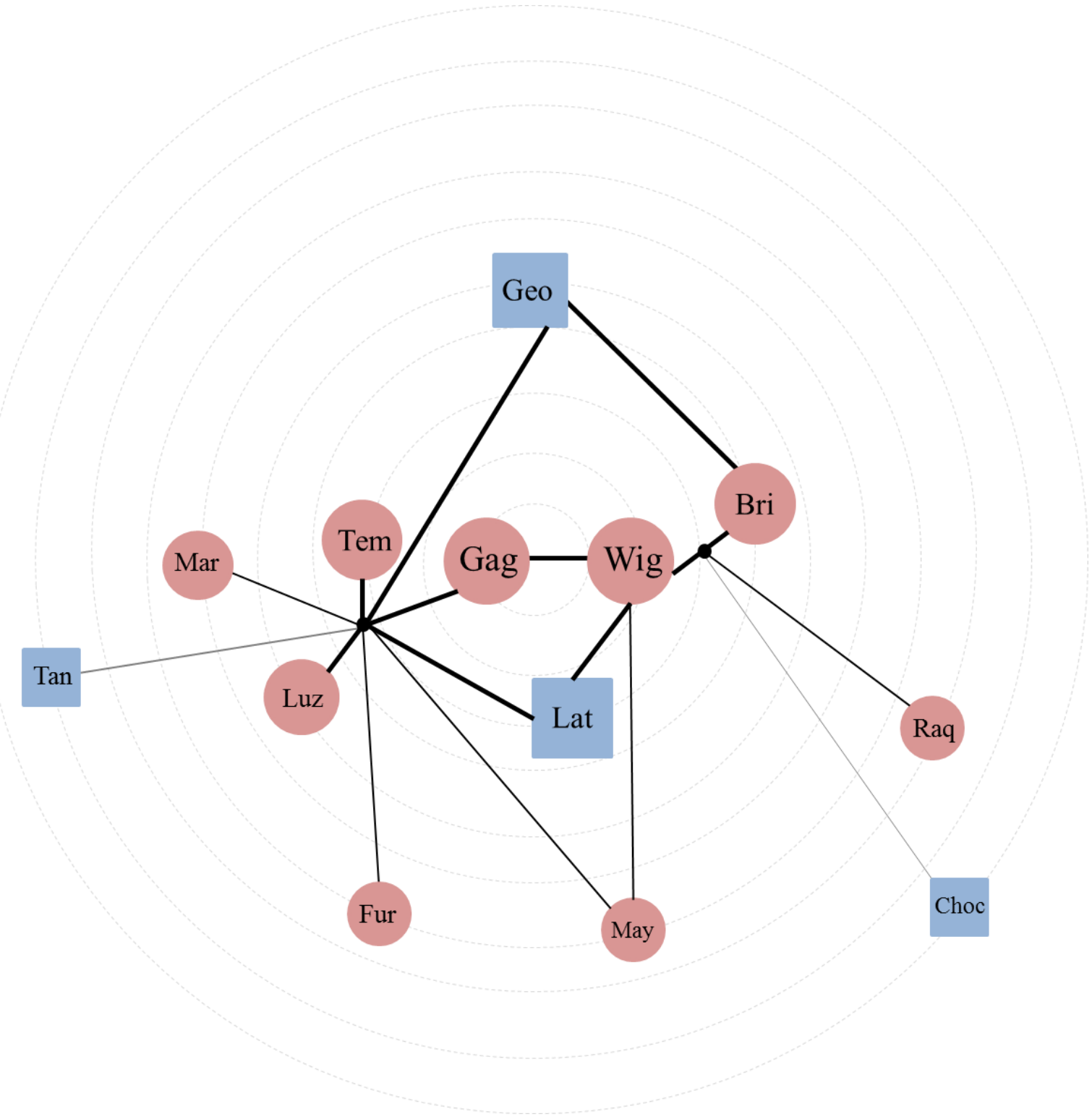

Figura 4.5. Representação da estrutura social das cobaias estudadas neste trabalho com base nos valores de IA, força e centralidade calculados para cada indivíduo. Círculos representam as fêmeas e quadrados representam os machos. A posição dos indivíduos se refere aos valores de centralidade do autovetor: quanto mais próximo ao centro, mais central é o indivíduo na estrutura da colônia. O tamanho dos símbolos é referente à força do indivíduo: quanto maior o símbolo, mais alto o valor de força do indivíduo. A espessura das linhas que conectam os indivíduos é referente aos valores de IA: quanto mais espessa a linha, mais forte é a associação entre os indivíduos. 


\subsection{TESTE DE PREFERÊNCIA}

Durante o teste de escolha, as fêmeas permaneceram mais tempo sozinhas no compartimento central do que em companhia de algum dos machos $(\mathrm{U}=11 ; p=0,000)$ (Tabela 4.4).

Tabela 4.4. Comparação entre os postos médios do tempo que as fêmeas de cobaia (Cavia porcellus) passaram sozinhas no compartimento central do cercado experimental em relação ao tempo que passaram com os machos presentes nos testes de escolha segundo o teste de Mann-Whitney (nível de significância: 5\%).

\begin{tabular}{lc}
\hline \multicolumn{1}{c}{ Situação } & Soma dos postos \\
\hline Sozinha (Compartimento Central) & $334^{\mathrm{a}^{*}}$ \\
Com macho (Compartimentos nas extremidades) & $131^{\mathrm{b}}$ \\
\hline * Postos médios seguidos de pelo menos uma letra igual indica postos médios estatisticamente iguais $(p>0,05)$.
\end{tabular}

Entretanto, mesmo que as fêmeas tenham permanecido mais tempo sozinhas, há diferença no tempo em que as fêmeas permaneceram com cada um dos machos, que variou também de acordo com o par que era apresentado as fêmeas. De modo geral, Chocolate foi o macho com o qual as fêmeas permaneceram menos tempo. As fêmeas permaneceram mais tempo com Latrel $\left(\mathrm{H}_{(2)}=12,48, p=0,001\right)$ e George $\left(\mathrm{H}_{(2)}=22,48, p=0,000\right)$ quando estes machos eram pareados com Chocolate. Porém, quando Latrel e George foram pareados, não houve diferença no tempo em que as fêmeas permaneceram com cada um deles $\left(\mathrm{H}_{(2)}=11\right.$, $p=0,004$ ) (Tabela 4.5). A Figura 4.6 ilustra os resultados do teste de preferência.

Tabela 4.5. Comparação entre os postos médios do tempo que as fêmeas permaneceram com cada um dos machos nos diferentes pareamentos realizados nos testes de escolha segundo teste de Kruskal-Wallis seguido de post-hoc Student-Newman-Keuls (nível de significância: 5\%).

\begin{tabular}{ccc}
\hline Pareamento & Macho & Posto médio \\
\hline \multirow{2}{*}{ Chocolate x Latrel } & Chocolate & $13,86^{\mathrm{a}}$ \\
& Latrel & $24,53^{\mathrm{b}}$ \\
Chocolate x George & Chocolate & $12,2^{\mathrm{c}}$ \\
& George & $21,93^{\mathrm{d}}$ \\
Latrel x George & Latrel & $15,73^{\mathrm{e}^{*}}$ \\
& George & $21,76^{\mathrm{e}}$ \\
\hline
\end{tabular}

\footnotetext{
* Postos médios seguidos de pelo menos uma letra igual indica postos médios estatisticamente iguais (p>0,05).
} 

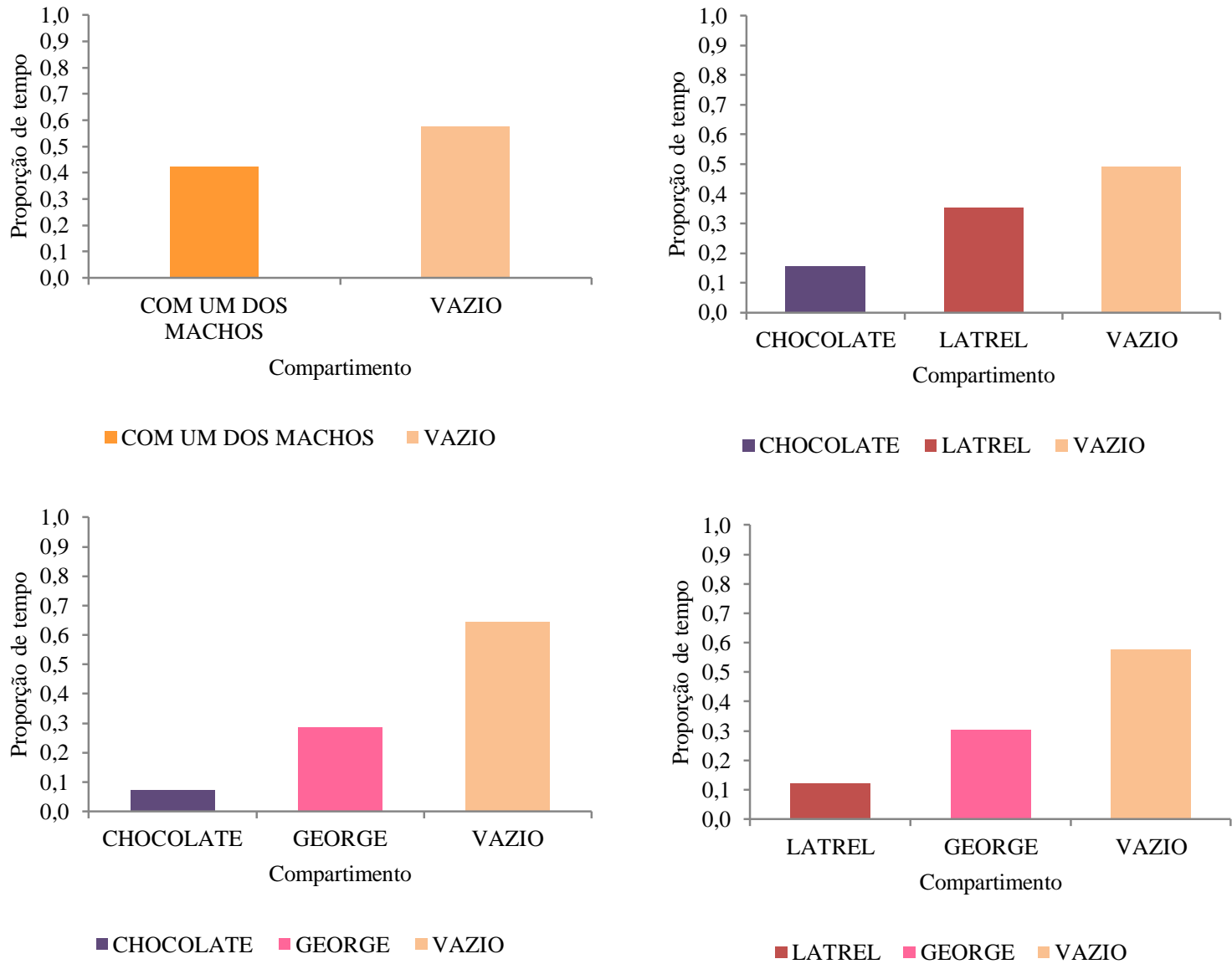

Figura 4.6. Representação gráfica da proporção de tempo que as fêmeas permaneceram em cada compartimento do cercado experimental, que continha um dos machos ou estava vazio no teste de escolha nos diferentes pareamentos realizados. (A) Comparação entre o tempo que as fêmeas permaneceram sozinhas e o tempo que elas permaneceram com os machos (soma do tempo dos dois machos presentes em cada pareamento); (B) Comparação do tempo que as fêmeas permaneceram com cada um dos machos e sozinhas no pareamento Chocolate x Latrel; (C) Comparação do tempo que as fêmeas permaneceram com cada um dos machos e sozinhas no pareamento Chocolate x George; (D) Comparação do tempo que as fêmeas permaneceram com cada um dos machos e sozinhas no pareamento Latrel x George.

A comparação individual do tempo que cada fêmea passou com cada um dos machos, comparando os resultados dos testes com os três pares de machos, apontou diferença apenas no tempo em que Lady Gaga passou com Chocolate e Latrel quando os dois foram pareados, sendo maior o tempo que ela passou com Latrel. Em todos os outros pareamentos não houve diferença nos tempos individuais em que cada fêmea passou com um dos machos nos três diferentes pareamentos. 
Tabela 4.6. Média, mediana, valor mínimo e valor máximo da porcentagem de tempos que cada fêmea permaneceu com um dos machos nos diferentes pareamentos.

\begin{tabular}{|c|c|c|c|c|c|c|}
\hline \multirow[b]{2}{*}{ Fêmea } & \multirow[b]{2}{*}{ Pareamento } & \multirow[b]{2}{*}{ Macho } & \multicolumn{4}{|c|}{ Duração (\%) } \\
\hline & & & Média & Mediana & $\begin{array}{l}\text { Valor } \\
\text { mínimo }\end{array}$ & $\begin{array}{l}\text { Valor } \\
\text { máximo }\end{array}$ \\
\hline \multirow{6}{*}{ Wiggly } & \multirow{2}{*}{ Chocolate x Latrel } & Chocolate & 23,5 & 10,7 & 3,7 & 56,2 \\
\hline & & Latrel & 17,6 & 13,5 & 7,9 & 31,3 \\
\hline & \multirow[t]{2}{*}{ Chocolate x George } & Chocolate & 4,9 & 5,4 & 3,3 & 5,8 \\
\hline & & George & 39 & 51,4 & 8,2 & 57,4 \\
\hline & \multirow[t]{2}{*}{ Latrel x George } & Latrel & 4,6 & 3,2 & 2,7 & 8 \\
\hline & & George & 18,2 & 12,7 & 2,9 & 39,1 \\
\hline \multirow{6}{*}{ Luzi } & \multirow{2}{*}{ Chocolate x Latrel } & Chocolate & 22,6 & 20,5 & 12,2 & 35,2 \\
\hline & & Latrel & 51,1 & 48,3 & 25,4 & 79,6 \\
\hline & \multirow[t]{2}{*}{ Chocolate $\mathrm{x}$ George } & Chocolate & 12,2 & 16,1 & 3,2 & 17,4 \\
\hline & & George & 56,3 & 41,6 & 36 & 91,4 \\
\hline & \multirow[t]{2}{*}{ Latrel x George } & Latrel & 17,5 & 0,9 & 0 & 51,7 \\
\hline & & George & 69,3 & 97,4 & 10,9 & 99,5 \\
\hline \multirow{6}{*}{ Lady Gaga } & \multirow[t]{2}{*}{ Chocolate x Latrel } & Chocolate & 6,2 & 8,9 & 0,3 & 9,5 \\
\hline & & Latrel & 64,8 & 61,2 & 38,6 & 94,5 \\
\hline & \multirow[t]{2}{*}{ Chocolate x George } & Chocolate & 8,7 & 7,1 & 1,8 & 17,2 \\
\hline & & George & 3 & 2,9 & 0,7 & 5,5 \\
\hline & \multirow[t]{2}{*}{ Latrel x George } & Latrel & 12,3 & 5,9 & 6 & 30,6 \\
\hline & & George & 2,9 & 1,6 & 0,5 & 6,7 \\
\hline \multirow{6}{*}{ Marin } & \multirow{2}{*}{ Chocolate x Latrel } & Chocolate & 6,5 & 8,7 & 1 & 9,7 \\
\hline & & Latrel & 15,2 & 19 & 4 & 22,6 \\
\hline & \multirow[t]{2}{*}{ Chocolate $\mathrm{x}$ George } & Chocolate & 6,2 & 5,2 & 3,8 & 9,6 \\
\hline & & George & 18,3 & 7,9 & 6,2 & 40,7 \\
\hline & \multirow[t]{2}{*}{ Latrel x George } & Latrel & 20,3 & 15,3 & 14 & 31,5 \\
\hline & & George & 21,3 & 24,8 & 1,6 & 37,5 \\
\hline \multirow{6}{*}{$\begin{array}{l}\text { Fúria da } \\
\text { Noite }\end{array}$} & \multirow{2}{*}{ Chocolate x Latrel } & Chocolate & 18,7 & 18,1 & 15,1 & 23 \\
\hline & & Latrel & 28,4 & 31,4 & 9,8 & 44 \\
\hline & \multirow[t]{2}{*}{ Chocolate $\mathrm{x}$ George } & Chocolate & 3,9 & 3,6 & 2,3 & 5,7 \\
\hline & & George & 25,9 & 14,4 & 4 & 59,3 \\
\hline & \multirow[t]{2}{*}{ Latrel x George } & Latrel & 5,1 & 5,2 & 1,4 & 8,8 \\
\hline & & George & 39,6 & 39,2 & 0,7 & 78,8 \\
\hline
\end{tabular}




\section{DISCUSSÃO}

Nesse trabalho investigamos como as fêmeas se organizavam em colônia sob a óptica das redes e, pela primeira vez, contrapusemos as decisões das fêmeas em relação à associação preferencial com um macho, às suas decisões por um companheiro social macho privado de exercer uma influência física sobre elas. A seguir discutiremos esses e outros resultados à luz das associações preferenciais e da formação de vínculo em mamíferos.

\subsection{ASSOCIAÇÕES PREFERENCIAIS EM COLÔNIA}

As diversas espécies de mamíferos podem se organizar em diferentes tipos de unidades sociais, como pares monogâmicos, haréns e unidades isosexuais (FEDIGAN, 1982; DIXSON, 1998), e nas cobaias não é diferente. A estrutura social típica de cobaias vivendo em colônia é a existência de um ou mais haréns, formados por um macho dominante, as fêmeas associadas a ele e machos subordinados tolerados pelo macho dominante (JACOBS, 1976; SACHSER; HENDRICHS, 1982; SACHSER, 1986, SACHSER, 1998). Alguns machos, com postos baixos na hierarquia e que não são aceitos por um macho dominante, vagam pela colônia como "satélites" (ASHER et al., 2008) e não possuem relação mais próxima com os outros indivíduos (JACOBS, 1976; SACHSER; HENDRICHS, 1982; SACHSER, 1986, SACHSER, 1998). Os animais da colônia estudada apresentaram o mesmo tipo de organização social já descrita em literatura para a espécie, formando pequenas agregações preferenciais entre fêmeas e entre machos e fêmeas, com associações mais fortes entre si do que com os outros indivíduos da colônia.

Os prováveis fatores que contribuem para uma estrutura social estável e pouco agressiva entre as cobaias, em relação às outras espécies do gênero, são: a grande tolerância entre coespecíficos, atribuída ao processo de domesticação, e a habilidade de estabelecer hierarquia e vínculos sociais entre os indivíduos (SACHSER, 1998). A formação de vínculos mais conhecida nas cobaias se dá na relação entre mãe e filhotes. A formação deste vínculo é tão importante para os filhotes que, quando são separados da mãe, apresentam claros sinais de estresse (HENNESSY et al., 1988). Estes sinais são minimizados quando o contato com a mãe é reestabelecido, evidenciando a importância da ligação mãe-filhote (HENNESSY et al.,1995; HENNESSY et al., 1996). A presença de outros indivíduos familiares ou não familiares ao filhote também diminui os sinais de estresse causados pelo isolamento do 
filhote, o que ressalta a importância dos vínculos sociais (HENNESSY et al., 2000; TOKUMARU; ADES; MONTICELLI, 2015).

Nas relações entre adultos, também é possível notar a formação de vínculo entre machos e fêmeas. As fêmeas dirigem a maior parte de seus comportamentos afiliativos ao macho que é seu parceiro social (SACHSER, 1986). Os machos, por sua vez, protegem as fêmeas de prováveis interações coercitivas de outros machos (KAISER et al., 2003b). Assim, um efeito similar ao que indivíduos adultos causam ao filhote em isolamento também pode ser visto entre adultos, tanto em machos quanto em fêmeas, em relação a seus parceiros sociais (SACHSER et al., 1998; KAISER et al., 2003a): a presença de um indivíduo familiar em situações de isolamento diminui os sintomas de estress. Mas, diferente do que acontece entre adultos e filhotes em que a presença de qualquer indivíduo adulto minimiza os efeitos do estresse em filhotes, coespecíficos não familiares causam um mesmo efeito menos efetivo do que o parceiro social entre cobaias adultas (SACHSER et al., 1998; KAISER et al., 2003a).

Uma das funções dos vínculos em um sistema social é a possibilidade dos parceiros proverem suporte social uns aos outros (MENDOZA; MASON, 1986; SACHSER et al., 1998, KAISER et al., 2003a). Suporte social pode ser definido como as informações que chegam ao indivíduo e indicam que o mesmo é amparado por outros do grupo (COBB, 1976). Como a habilidade de prover suporte não pode ser exercida por qualquer indivíduo (von HOLST, 1998), o vínculo social é uma provável garantia da disponibilidade e acessibilidade do parceiro que, em situações estressantes minimiza as consequências fisiológicas ao estresse (HENRY, 1993; von HOLST, 1998).

Para as fêmeas, outra potencial vantagem da associação com os machos, além do suporte social, poderia ser a diminuição das chances de infanticídio por um macho invasor (PALOMBIT, 2000). Em muitas espécies, machos invasores ou machos que acabaram de tomar posse de um harém muitas vezes matam os filhotes de outros machos muitas vezes para forçar o estro nas fêmeas. Porém, em cobaias não há relatos de infanticídio por parte dos machos. Machos conseguem dividir o mesmo espaço, o que provavelmente está relacionado com a maior tolerância entre coespecíficos e a diminuição da agressividade nas cobaias, e se organizam de forma que cada macho possua seu grupo de fêmeas associadas. Situação diferente é vista em uma das espécies selvagens do gênero: em Cavia aperea, machos não se toleram no mesmo espaço e o pai pode matar os filhotes machos caso eles não dispersem ao atingir a maturidade sexual (SACHSER, 1998). A vantagem para as fêmeas em formarem 
vínculos com os machos pode ser, então, uma condição que apareceu anteriormente no gênero.

A vantagem do vínculo em associações intersexuais, para os machos, é evitar que a fêmea copule com outros machos. Há indícios de que as associações entre cobaias machos e fêmeas são formadas durante a gravidez (JACOBS, 1976). Esta é uma estratégia eficiente para macho, pois o estro pós-parto é um período mais provável de receptividade da fêmea do que o estro que ocorre ao longo do ciclo estral da fêmea. Além disto, a formação dos vínculos durante a gravidez confere ao macho uma maior probabilidade de conseguir copular primeiro e mais vezes com as fêmeas do que os outros machos.

Assim, a vantagem reprodutiva do macho associado (associatade male, JACOBS, 1976; “owner", SACHSER; HENDRICHS, 1982) é favorecida pela forma como as cobaias se organizam (SACHSER, 1998). O vínculo entre machos e fêmeas e consequente guarda das parceiras dificultam o acesso de outros machos às fêmeas (JACOBS, 1976; SACHSER; HENDRICHS, 1982). Isto reforça a hipótese proposta nos resultados de que Latrel é o macho dominante da colônia e associado a praticamente todas as fêmeas, enquanto George é um macho subordinado a ele. Além do empate no teste de escolha, os índices de associação do George com as fêmeas são muito próximos dos índices que Latrel estabelece com elas, o que exclui a possibilidade de haver mais de um harém na colônia. Se Latrel e George fossem dois machos associados a fêmeas diferentes, os índices de associação deles com as mesmas fêmeas seriam bem diferentes.

Também foi observado neste trabalho um forte vinculo entre as fêmeas, com variação entre as díades observadas, que não foi reportado com detalhes nos outros estudos sobre a estrutura social das cobaias. Fala-se apenas que os machos se associam a mais de uma fêmea mas não se descreve se estas fêmeas possuem algum tipo de vínculo entre si. Apesar de não haver descrição desta forte associação entre as fêmeas em trabalhos anteriores, há na literatura descrições desta condição em outras espécies de mamíferos (WEIDT et al., 2008; BEST et al., 2013; ARCHIE, et al., 2014; MALYJURKOVA et al.,2014). O principal contexto da associação entre fêmeas em mamíferos sociais é a cooperação, principalmente em relação ao cuidado com os filhotes, levando a uma variação na aptidão entre fêmeas que formam e que não formam vínculos entre si (ARCHIE et al., 2014; WEIDT et al., 2008). Embora haja aloamamentação em cobaias e preás, não há dados suficientes neste trabalho para sugerirmos cooperação entre as fêmeas. O mais provável é que o alocuidado em Cavia seja um by-product da vida social e não uma adaptação (MONTICELLI; TOKUMARU; ADES, in press). 
As associações preferenciais características da estrutura social das cobaias estão presentes também em outros roedores, principalmente entre os caviomorfos, como em capivaras (FERRAZ, et al 2013; GERALDI, 2014). Quando o sistema social de espécies filogeneticamente próximas pode ser considerado homogêneo, mesmo que o ambiente de cada uma delas seja diverso, podemos dizer que a socialidade é uma resposta adaptada, uma vez que não foi determinada por uma pressão seletiva recente. Assim o sistema social provavelmente foi selecionado em um ambiente comum em espécies ancestrais e persistiu nas populações atuais (ROWE; HONEYCUTT, 2002). É possível, então, inferir que a tendência à formação de vínculos com coespecíficos é uma característica ancestral do grupo e não apenas mais uma das consequências do processo de domesticação das cobaias (JACOBS, 1976, SACHSER, 1986).

A identificação e descrição das associações preferências das cobaias neste estudo foram estimadas com cálculo do índice de associação e a abordagem das redes sociais. $\mathrm{O}$ índice de associação entre os animais nos forneceu informações sobre a proporção de tempo em que os animais estavam associados e, consequentemente interagindo. Animais que são associados são frequentemente encontrados juntos nos locais de descanso e de alimentação e muitas vezes podem ser vistos se locomovendo juntos, geralmente com o macho seguindo as fêmeas (JACOBS, 1976). Assim, o índice de associação pode ser considerado uma medida confiável sobre as preferências sociais dos indivíduos.

Este é o primeiro estudo com cobaias que utilizou as redes sociais para estabelecer o papel de cada indivíduo dentro da colônia. Há muitos estudos que buscaram descrever a estrutura social das cobaias, mas todos utilizando a hierarquia entre os machos para tentar entender as características de um indivíduo na colônia. As redes sociais, além de permitirem a avaliação do status cada um dos animais, gerando informações sobre como cada um deles se relaciona com os outros membros do grupo, permitem também observar a força das relações intra e intersexuais, mostrando que houve uma forte ligação entre fêmeas, informação negligenciada em estudos anteriores.

\subsection{A ESCOLHA DAS FÊMEAS}

Os resultados no teste de escolha refletem os padrões de associação dos indivíduos em colônia, sendo a escolha da fêmea altamente relacionada com as características das relações entre os indivíduos em colônia. Mas qual seria a raiz desta relação? 
Trabalhos sobre organização social em cobaias olharam apenas pelo ponto de vista do macho, como eles se organizam entre eles e como demonstram preferência pelas fêmeas e dominância sobre elas. JACOBS (1976) e SACHSER;HENDRICHS (1982) descreveram que o macho demonstra afinidade por uma fêmea cortejando ela o dobro de vezes do que corteja outras fêmeas. Mas e as fêmeas, também demonstram preferência pelos machos?

Apesar de alguns autores dizerem que há indícios de que as fêmeas não são passivas à escolha do macho (JACOBS, 1976; SACHSER, 1986), não houve investigação sobre a preferencia de fêmeas cobaias. Este é o ponto inovador deste trabalho. Investigamos não só como as fêmeas se organizam em colônia e a formação de associações intersexuais, mas também se os padrões de associação se repetem em ambiente controlado em que a variável “comportamento dos machos" foi minimizada. Assim, o cálculo dos índices de associação das díades intersexuais e o teste de escolha permitiram medir a preferência social das fêmeas pelos machos.

Estudos realizados em cativeiro com outros roedores, sob condições controladas que minimizam os efeitos de competição entre os machos e que permitem que a fêmea escolha livremente seu parceiro, já mostraram que as fêmeas tem preferência por machos específicos (WEBSTER; WILLIAMS; DEWSBURRY, 1982; HORNE; YLONEN, 1996; HOHOFF; FRANKEN; SACHSER, 2003). HOHOFF (2002) já havia testado se fêmeas de Cavia aperea demonstrariam preferência por um macho específico, sob o mesmo paradigma aqui adotado, com machos privados de sair de um compartimento e a fêmea podem escolher ficar só ou com um de dois machos. Apesar de algumas fêmeas terem copulado com mais de um macho, a autora observou que elas escolhiam um macho preferido para passar maior parte do tempo e que este macho era o pai de seus filhotes, não havendo multipaternidade. ADRIAN e colaboradores (2008b) também usaram este mesmo paradigma para testar a preferência social e sexual em outro cavídeo (Galea monasteriensis), comparando a preferência das fêmeas no teste de escolha com a paternidade dos filhotes que nasceram após os testes e corroborando que a preferência social das fêmeas refletia na paternidade dos filhotes.

Os testes de preferência deste estudo não foram realizados com fêmeas receptivas, não havendo fêmeas grávidas ao final dos testes. Contudo, ao longo dos estudos dos animais em colônia tivemos, ao todo, 14 ninhadas de 7 fêmas diferentes. $\mathrm{O}$ material genético destes filhotes já foram coletados e enviados para o Prof. Oriol Vidal, da Universitat di Girona (Espanha) para que o teste de paternidade pudesse ser feito, uma vez que não é possível determinar com certeza quem é o pai dos filhotes apenas com observações comportamentais. $\mathrm{O}$ resultados dos testes de paternidade nos permitirão concluir se a preferência social das 
fêmeas está relacionada a escolha do pai dos filhotes. Além disto, também seremos capazes de inferir se há multipaternidade em Cavia porcellus, o que não é possível no momento devido a falta de estudos a este respeito. Estudos em cativeiro com Cavia aperea (HOHOFF, 2002), espécie selvagem próxima às cobaias, não encontraram multipaternidade nas ninhadas. Já na natureza, foi registrada baixa taxa de multipaternidade (ASHER et al., 2008).

Mesmo podendo existir diferença entre a escolha que a fêmea faça por parceiros sociais e pelo pai de seus filhotes, testes de escolha que avaliam o tempo em que as fêmeas se associam socialmente a um macho tem sido utilizados para inferir as preferências reprodutivas das fêmeas (ADRIAN et al., 2008a). Além disto, é provável que a escolha social da fêmea esteja relacionada a atributos dos machos que possam lhe garantir sucesso reprodutivo. Testes de preferência realizados em Cavia aperea, que utilizam como critério de preferência o tempo que as fêmeas passam com um macho específico, demonstraram que as fêmeas preferem machos que as cortejam for mais tempo (HOHOFF, 2002) e que escolhem como parceiros sociais, e também pais de seus filhotes, machos com maior peso corporal (ADRIAN et al., 2008a).

Considerando o papel das fêmeas na formação das associações intersexuais e na escolha de seus parceiros, sociais e/ou sexuais, o macho precisaria sinalizas às fêmeas seus atributos para que elas possam fazer suas escolhas. É a partir das exibições de corte do macho que as fêmeas podem conhecer seus atributos e escolher como parceiro social e, possivelmente, sexual. Os machos de Cavia tem uma exibição de corte complexa quando comparada a outros mamíferos. Durante a corte, o macho persegue a fêmea e eventualmente marca com sua glândula anal a própria fêmea ou partes do ambiente onde ela está. Ele segue a fêmea fazendo a rumba, um movimento ritmado dos quadris, e emitindo um chamado de corte, o purr (KING, 1956; MONTICELLI, 2005). JACOBS (1976) notou que é comum machos cortejarem fêmeas mesmo que elas não estivessem receptivas e que a intensidade deste cortejo era maior durante a gravidez das fêmeas, principalmente no período final da gestação. Como dito anteriormente, é provavelmente neste momento que os vínculos são formados.

Assim, a preferência demonstrada pelas fêmeas no teste de escolha provavelmente está relacionada aos atributos dos machos testados. Este é um dos possíveis motivos para o empate entre George e Latrel como machos escolhidos e para uma possível rejeição do Chocolate. É provável que George e Latrel possuam atributos que agradem as fêmeas e que Chocolate não os possua. As fêmeas escolhem machos que possam de alguma forma contribuir para seu sucesso reprodutivo, com recursos materiais para ela e a prole 
(HIDALGO-GARCIA, 2006; PIKE et al., 2007) ou com recursos genéticos herdados pela prole (COLEGRAVE; KOTIAHO; TOMKINS, 2002; MAYS; HILL, 2004). Em geral, as fêmeas possuem vários parâmetros de seleção para escolher o macho que será seu parceiro, como dominância, altos níveis de testosterona, coloração mais brilhante, padrão genético heterogêneo, entre outros (CLUTTON-BROCK; MCAULIFFE, 2009).

Os atributos que levam uma fêmea cobaia a escolher seu parceiro serão investigados no projeto de pesquisa que dará continuidade a este trabalho, em que será traçada a relação da escolha das fêmeas, os atributos dos machos e os diversos canais de comunicação utilizados na corte. 


\section{CONClusões Finais}

A grande contribuição da nossa pesquisa é mostrar a formação de associações preferenciais do ponto de vista das fêmeas de mamíferos. A falta desta abordagem em estudos anteriores sobre a estrutura social das cobaias não evidenciava o papel ativo das fêmeas na formação das associações intersexuais e o vínculo entre as fêmeas.

Por muito tempo o comportamento das fêmeas foi negligenciado em estudos de vínculos sociais e escolhas de parceiros. Neste estudo, pôde-se concluir que as fêmeas tem papel ativo na organização social e na formação de vínculos e que a dominância entre os machos e a defesa das fêmeas, apesar de serem fortes elementos na estrutura social das cobaias, não são os únicos fatores atuando na dinâmica social deste grupo de roedores e possivelmente em outros mamíferos de forma geral.

A continuação desta pesquisa complementará o entendimento das relações sociais e reprodutivas das cobaias. No Doutorado investigaremos a preferência sexual das fêmeas, testando diferentes tipos de machos, em situação experimental e em colônia e medindo o sucesso reprodutivo destes machos, buscando entender quais características as fêmeas buscam naquele macho que será o pai dos filhotes e com quem ela forma os vínculos sociais. 


\section{REFERÊNCIAS BIBLIOGRÁFICAS}

ADRIAN, O.; DEKOMIEN, G.; EPPLEN, J. T.; SACHSER, N. Body weight and rearing conditions of males, female choice and paternities in a small mammal, Cavia aperea. Ethology, v. 114, n. 9, p.897-906, 2008a.

ADRIAN, O.; KAISER, S.; SACHSER, N.; JANDEWERTH, P.; LÖTTKER, P.; EPPLEN, J. T.; HENNESSY, M. B. Female influences on pair formation, reproduction and male stress responses in a monogamous cavy (Galea monasteriensis). Hormones and behavior, v. 53, n. 3, p. 403-412, 2008.

ADRIAN, O.; SACHSER, N. Diversity of social and mating systems in cavies: a review. J. Mammal., v. 92, n. 1, p. 39-53, 2011.

ARCHIE, E. A.; TUNG, J.; CLARK, M.; ALTMANN, J.; ALBERTS, S. C. Social affiliation matters: both same-sex and opposite-sex relationships predict survival in wild demale baboons. Proceedings of the Royal Society B, v. 281, 2014.

ASHER, M.; OLIVEIRA, E. S.; SACHSER, N. Social system and spatial organization of wild guinea pigs (Cavia aperea) in a natural low density populations. $\mathbf{J}$. Mammal., v. 85, n.4, pp. 788-796, 2004.

ASHER, M.; LIPPMANN, T.; EPPLEN, J. T.; KRAUS, C.; TRILLMICH, F.; SACHSER, N. Large males dominate: ecology, social organization, and mating system of wild cavies, the ancestors of the guinea pig. Behavioral Ecology and Sociobiology, v. 62, n. 9, p.1509-1521, 2008.

BATEMAN, A. J. Intra-sexual selection in Drosophila. Heredity, v. 2, p. 349-368, 1948.

BEISIEGEL, B. M. Comportamento paterno e dinâmica familiar na cobaia doméstica. Dissertação de Mestrado. Instituto de Psicologia, Universidade de São Paulo, São Paulo. 1993. 
BEJDER, L.; FLETCHER, D.; BRAGER, S. A method for testing association patterns of social animals. Animal Behaviour, v. 56, p. 719-725, 1998.

BEST, E. C.; SEDDON, J. M.; DWYER, R. G.; GOLDIZEN, A. W. Social preference influences female community structure in a population of wild eastern grey kangaroos. Animal Behaviour, v. 86, n. 5, p.1031-1040. 2013.

BORRIES, C.; LARNEY, E.; LU, A.; OSSI, K.; KOENIG, A. Costs of group size: lower developmental and reproductive rates in larger groups of leaf monkeys. Behavioral ecology, v. 19, p.1186-1191, 2008.

BRENT, L. J.; CHANG, S. W.; GARIÉPY, J. F.; PLATT, M. L. . The neuroethology of friendship. Annals of the New York Academy of Sciences, v. 1316, n. 1, p.1-17, 2014.

BROAD, K. D.; CURLEY, J. P.; KEVERNE, E. B. Mother-infant bonding and the evolution of mammalian social relationships. Philosophical Transactions of the Royal Society of London B: Biological Sciences, v. 361, n. 1476, p. 2199-2214, 2006.

CABRERA, A. Roedores argentinos de la familia Caviidae. Buenos Aires: Publicacion de la Escuela de Veterinaria, Universidad de Buenos Aires. v. 6, 1953. 93p.

CAIRNS, S.J; SCHWAGER, S.J. A comparison of association indices. Animal Behaviour, v. 35, p. 1454-1469, 1987.

CAMERON, E. Z.; SETSAAS, T. H.; LINKLATER, W. L. Social bonds between unrelated females increase reproductive success in feral horses. Proceedings of the National Academy of Sciences, v. 106, n. 33, p. 13850-13853, 2009.

CARTER, N. D. Carbonic anhydrase isozymes in Cavia porcellus, Cavia aperea and their hybrids. Comp. Biochem. Pshysiol., v. 43b, p. 743-747, 1972.

CARTER, K.D.; BRAND, R.; CARTER, J.K.; SHORROCKS, B.; GOLDIZEN, A. Social networks, long-term associations and age-related sociability of wild giraffes. Animal Behaviour, v. 86, p. 901-910, 2013. 
CHANG, S. W.; BRENT, L. J.; ADAMS, G. K.; KLEIN, J. T.; PEARSON, J. M.; WATSON, K. K.; PLATT, M. L.. Neuroethology of primate social behavior. Proceedings of the National Academy of Sciences, v. 110, Supplement 2, p. 10387-10394, 2013.

CLUTTON-BROCK, T. Cooperation between non-kin in animal societies. Nature, v. 462, n. 7269, p. 51-57, 2009.

CLUTTON-BROCK, T.; ALBON, S. D.; GIBSON, R. M.; GUINESS, F. E. The logical stag: adaptive aspects of fighting in red deer. Animal Behavior, v. 27, p. 211-225, 1979.

CLUTTON-BROCK, T.; MCAULIFFE, K. Female mate choice in mammals. The Quarterly Review of Biology, v. 84, n. 1, p. 3-27, 2009.

COBB, S. Social support as a moderator of life stress. Psychosomatic medicine, v. 38, n. 5, p. 300-314, 1976.

COLEGRAVE, N., KOTIAHO J. S., TOMKINS J. L. Mate choice or polyandry: reconciling genetic compatibility and good genes sexual selection. Evolutionary Ecology Research v. 4, p. 911-917, 2002.

CORDS, M. Friendships, alliances, reciprocity and repair. In: WHITEN, A. Machiavellian Intelligence II: Extensions and Evaluations, Cambridge University Press, Cambridge, p. 24-49, 1997.

CROFT, D.P.; JAMES, R.; KRAUSE, J. Exploring Animal Social Networks. Princeton University Press, Princeton, 2008.

DARWIN, C. The Descent of Man, and Selection in Relation to Sex. London: John Murray, 1871.

DAVIES, N. B., LUNDBERG, A. Food distribution and a variable mating system in the dunnock, Prunella modularis. Journal of Animal Ecology, v. 53, p. 895-912, 1984. 
DIXSON, AF. Primate sexuality: comparative studies of the prosimians, monkeys, apes, and human beings. Oxford: Oxford University Press. 1998.

DREWS, C. Contests and patterns of injuries in free-ranging male baboons (Papio cynocephalus). Behaviour. v. 133, p. 443-474, 1996.

DUNBAR, R. I. M. The social role of touch in humans and primates: behavioural function and neurobiological mechanisms. Neuroscience \& Biobehavioral Reviews, v. 34, n. 2 , p. $260-268,2010$.

DUNBAR, R. I. M; SHULTZ, S. Bondedness and sociality. Behaviour, v. 147, n. 7, p. $775-803,2010$.

DUNNUM, J. L.; SALAZAR-BRAVO, J. Molecular systematics, taxonomy and biogeography of the genus Cavia (Rodentia: Caviidae). Journal of Zoological Systematics and Evolutionary Research, v. 48, n. 4, p. 376-388, 2010.

DURRELL, J. L., S.; I. A., O’CONNELL, N. E.; WHITEHEAD, H. Do pigs form preferential associations? Applied Animal Behaviour Science,v. 89, n. 1, p.41-52, 2004.

EBENSPERGER, L.A. A review of the evolutionary causes of rodent group-living. Acta Theriol., v. 46, n. 2, p.115-144. 2001.

FEDIGAN, LM. Primate paradigms: sex roles and social bonds. Montreal: Eden Press. 1982.

FERRAZ, K. M. P. M. B.; IZAR, P.; SATO, T.; NISHIDA, S. M. Social and spatial Relationships of Capybaras in a Semi-confined Production System. In: MOREIRA, J. R.; FERRAZ, K. M. P. M. B.; HERRERA, E. A.; MACDONALD, D. W. (Eds.). Capybara: biology, use and conservation of an exceptional neotropical species. New York: Springer, 2013.

FISHER, R. A. The genetical theory of natural selection. Oxford: Claredon, 1930. 
FURNARI, N. Corte intra e interespecífica em cobaias (Cavia porcellus) e preás (Cavia aperea). Dissertação de Mestrado. Universidade de São Paulo. 2006.

FURNARI, N. Comportamento e organização social do préa Cavia intermedia, uma espécie endêmica das Ilhas Moleques do Sul, Santa Catarina. Tese de Doutorado. Universidade de São Paulo. 2011.

GARROWAY, C. J.; BOWMAN, J.; WILSON, P. J. Complex social structure of southern flying squirrels is related to spatial proximity but not kinship. Behavioral Ecology and Sociobiology, v. 67, n. 1, p. 113-122, 2013.

GERALDI, M. “Análise da estrutura social e sua relação com o chamado de alarme de um grupo de capivaras em condições de cativeiro". Monografia .Faculdade de Filosofia, Ciências e Letras de Ribeirão Preto, Universidade de São Paulo. 2014.

GINSBERG, J.R.; YOUNG, T.P. Measuring association between individuals or groups in behavioural studies. Anim. Behav., v. 44, p. 377-379, 1992.

HENNESSY, M. B. Both prevention of physical contact and removal of distal cues mediate cortisol and vocalization responses of guinea pig pups to maternal separation in a novel environment. Physiology \& behavior, v. 43, n. 6, p. 729-733, 1988.

HENNESSY, M. B., NIGH, C. K., SIMS, M. L.,; LONG, S. J. Plasma cortisol and vocalization responses of postweaning age guinea pigs to maternal and sibling separation: evidence for filial attachment after weaning. Developmental psychobiology, v. 28, n. 2, p.103-115. 1995.

HENNESSY, M. B.; MAZZEI, S. J.; MCINTURF, S. M. The fate of filial attachment in juvenile guinea pigs housed apart from the mother. Developmental psychobiology, v. 29, n. 8, p. 641-651, 1996.

HENNESSY, M. B.; MAKEN, D. S.; GRAVES, F. C. Consequences of the presence of the mother or unfamiliar adult female on cortisol, ACTH, testosterone and behavioral 
responses of periadolescent guinea pigs during exposure to novelty. Psychoneuroendocrinology, v. 25, n. 6, p. 619-632, 2000.

HENRY, J. P. Psychological and physiological responses to stress: The right hemisphere and the hypothalamo-pituitary-adrenal axis, an inquiry into problems of human bonding. Integrative Physiological and Behavioral Science, v. 28, n. 4, p. 369-387, 1993.

HIDALGO-GARCIA, S. The carotenoid-based plumage coloration of adult Blue Tits Cyanistes caeruleus correlates with with the health status of their brood. Ibis, v. 148, p. 727 734, 2006.

HINDE, R. A. Interactions, relationships and social structure. Man, p. 1-17, 1976.

HOBSON, E. A.; AVERY, M. L.; WRIGHT, Ti. F. An analytical framework for quantifying and testing patterns of temporal dynamics in social networks. Animal Behaviour, v. 85, n. 1, p. 83-96, 2013.

HOHOFF, C. Female choice in three species of wild guinea pigs. 2002. 98p. Doutorade - Institute of Neuro and Bhavioral Biology, University of Münster, Münster, 2002

HOHOFF, C., FRANZEN, K., SACHSER, N. Female choice in a promiscuous wild guinea pig, the yellow-toothed cavy (Galea musteloides). Behavioral Ecology and Sociobiology, v. 53, n. 6, p. 341-349, 2003.

HORNE, T. J., YLÖNEN, H. Female bank voles (Clethrionomys glareolus) prefer dominant males; but what if there is no choice?. Behavioral Ecology and Sociobiology, v. 38, n. 6, p. 401-405, 1996.

JACOBS, W. W. Male-female associations in the domestic guinea pig.Animal learning \& behavior, v. 4, n. 1, p. 77-83, 1976.

KAISER, S., KIRTZECK, M., HORNSCHUH, G.,; SACHSER, N. Sex-specific difference in social support — a study in female guinea pigs. Physiology $\&$ behavior, v. 79, n. 2, p.297-303. 2003a. 
KAISER, S., HEEMANN, K., STRAUB, R. H., ; SACHSER, N. The social environment affects behaviour and androgens, but not cortisol in pregnant female guinea pigs. Psychoneuroendocrinology, v. 28, n. 1, p. 67-83. $2003 \mathrm{~b}$.

KAPPELER, P. M.; VAN SCHAIK, CP. Evolution of primate social systems. International Journal of Primatology, v. 23, n.4, pp. 707-740, 2002.

KING, J. A. Social relations of the domestic guinea-pigs living under semi-natural conditions. Ecology, v.37, pp.221-228, 1956.

KLEIMAN., DG. Patterns of behaviour in hystricomorph rodents. Symp. Zool. Soc. Lond., vol. 34: 171-209. 1974.

KRAUSE, J.; CROFT, D. P.; JAMES, R. Social network theory in the behavioural sciences: potencial applications. Behavioral Ecology and socialbiology, v. 62, pp. 15-27, 2007.

KÜNZL, C.; SACHSER, N. The behavioral endocrinology of domestication: A comparison between the domestic guinea pig (Cavia aperea $f$. porcellus) and its wild ancestor, the cavy (Cavia aperea). Horm. Behav., v. 35, pp. 28-37, 1999.

KURVERS, R.H.J.M.; ADAMCZYK, V.M.A.P.; KRAUS, R.H.S. Contrasting context dependence of familiarity and kinship in animal social networks. Animal Behaviour, v. 86, p. 993-1001, 2013.

LEHMANN, J.; ROSS, C. Baboon (Papio anubis) social complexity-a network approach. American Journal of Primatology, v. 73, n. 8, p. 775-789, 2011.

LIM, M. M.; YOUNG, L. J. Neuropeptidergic regulation of affiliative behavior and social bonding in animals. Hormones and behavior, v. 50, n. 4, p. 506-517, 2006

LOTT, D. F. Intraspecific variation in the social systems of wild vertebrates. Behaviour, v. 88, n. 3, p. 266-325, 1991. 
LUSSEAU, D.; NEWMAN, M.E.J. Identifying the role that animals play in their social networks. Proceedings of the royal society, v. 271, p.477-481, 2004.

MALYJURKOVA, L., HEJZLAROVA, M., VYMYSLICKA, P. J., BRANDLOVA, K. Social Preferences of Translocated Giraffes (Giraffa Camelopardalis Giraffa) in Senegal: Evidence for Friendship Among Females?. Agricultura Tropica et Subtropica, v. 47, n.1, p. $5-13.2014$

MANAF, P., OLIVEIRA, E. S. Female choice in Trinomys yonenagae, a spiny rat from the Brazilian Caatinga. Revista Brasileira de Zoociências, v. 11, n. 3, p. 201-208, 2009.

MAYS H. L., HILL, G. E. Choosing mates: good genes versus genes that are a good fit. Trends in Ecology and Evolution v. 19, n. 10, p. $554-559,2004$.

MENDOZA, S. P.; MASON, W. A. Contrasting responses to intruders and to involuntary separation by monogamous and polygynous New World monkeys. Physiology \& behavior, v. 38, n. 6, p. 795-801, 1986.

MONTICELLI, P. F. Comportamento e comunicação acústica no preá e na cobaia. 161p. 2005. Tese de Doutorado - Instituto de Psicologia, Universidade de São Paulo, São Paulo. 2005.

MONTICELLI, P. F.; TOKUMARU, R.S.; ADES, C. Suckling own or alien pup? It is the same to Cavia aperea. Mammalia, in press.

NOWAK, R. M. Cavies and Patagonian "Hares". In: NOWAK, R. M. Walker's mammals of the world. 5ed. Baltimore: John Hopkins University Press, pp. 1664-1666, 1991.

ORIONS, G. H. On the evolution of mating systems in birds and mammals. Am. Nat., v. 103, pp. 589-603, 1969 
PALOMBIT, R. A. Infanticide and the evolution of male-female bonds in animals. In: Infanticide by males and its implications. Cambridge University Press, Cambridge, p. 239$268,2000$.

PIKE, T. W, BlOUNT, J. D. LindSTROM, J., METCALFE, N. B. Dietary carotenoid availability influences a male's ability to provide parental care. Behavioural Ecology, v. 18, p. 1100-1105, 2007.

PIZZARI, T.; GARDNER, A. The sociobiology of sex: inclusive fitness consequences of inter-sexual interactions. Philosophical Transactions of the Royal Society of London B: Biological Sciences, v. 367, n. 1600, p. 2314-2323, 2012.

POPE, T. R. Reproductive success increases with degree of kinship in cooperative coalitions of female red howler monkeys (Alouatta seniculus). Behav. Ecol. Sociobiol., v. 48, p.253-267, 2000.

RAMOS-FERNANDEZ, G.; BOYER, D.; AURELI, F.; VICK, L. G.. Association networks in spider monkeys (Ateles geoffroyi). Behavioral Ecology and Sociobiology, v. 63, n. 7, p. 999-1013, 2009.

ROOD, J. P. Ecological and behavioural comparisions of three genera of argentine cavies. Anim. Behav. Monogr, v. 5, pp. 1-83, 1972.

ROWE, D. L.; HONEYCUTT, R. L. Phylogenetic Relationships, Ecological Correlates, and Molecular Evolution Within the Cavioidea (Mammalia, Rodentia). Mol. Biol. Evol., vol. 19(3): 263-277, 2002.

SACHSER, N. Different forms of social organization at high and low population densities in guinea pigs. Behaviour, vol. 97(3-4): 253-272. 1986.

SACHSER, N. Of domestic and wild guinea pigs: Studies in sociophysiology, domestication, and social evolution. Naturwissenschaften, v. 85, n. 7, pp. 307-317, 1998. 
SACHSER, N.; HENDRICHS, H. A longitudinal study on the social structure and its dynamics in a group of guinea pigs (Cavia aperea $f$. porcellus).Säugetierkundliche Mitteilungen, v. 30, p. 227-240, 1982.

SACHSER, N; DÜRSCHLAG, M; HIRZEL, D. Social relationships and the management of stress. Psychoneuroendocrinology, v. 23, n. 8, p. 891-904, 1998.

SACHSER, N.; RENNINGER, S.-V. Coping with new social situations: the role of social rearing in guinea pigs. Ethology ecology \& evolution, v. 5, n. 1, p. 65-74, 1991.

SANTOS, E. A. Comportamento e organização social do preá Cavia magna (Rodentia: Caviidae). Dissertação de Mestrado. Universidade de São Paulo. 2013.

SCHNELL, GD., WATT, DJ., e DOUGLAS, ME. Statistical comparison of proximity matrices: applications in animal behavior. Anim. Behav., v. 33, p. 239-253. 1985.

SEYFARTH, R. M.; CHENEY, D. L. The evolutionary origins of friendship. Annual review of psychology, v. 63, p. 153-177, 2012.

SILK, J. B. Using the 'F'-word in primatology. Behaviour, v. 139, n. 2-3, p. 421, 2002.

SILK, J. B.; BEEHNER, J. C.; BERGMAN, T. J.; CROCKFORD, C.; ENGH, A. L.; MOSCOVICE, L. R; CHENEY, D. L. Strong and consistent social bonds enhance the longevity of female baboons. Current Biology, v. 20, n. 15, p.1359-1361, 2010.

SIKES, R.S; GANNON, W.L. Guidelines of the American Society of Mammalogists for the use of wild mammals in research. Journal of Mammalogy. v. 92, pp. 235-253. 2011.

SPOTORNO, A. E.; VALlADARES, J. P.; MARÍN, J. C.; ZEBALlOS, H. Molecular diversity among domestic guinea-pigs (Cavia porcellus) and their close phylogenetic relationship with the Andean wild species (Cavia tschudii). Rev. Chil. Hist. Nat., v. 77, n. 2, pp. 243-250, 2004. 
SUSCKE, P. Socioecologia de Sapajus xanthosternos na Reserva Biológica de Una, sul da Bahia. Tese de Doutorado. Universidade de São Paulo. 2014

TOKUMARU, R. S.; ADES, C.; MONTICELLI, P. F. Social support does not require attachment: Any conspecific tranquilizes isolated guinea-pig pups. Applied Animal Behaviour Science, v. 171, p. 197-203, 2015.

TRILLMICH, F.; KRAUS, C.; KÜNKELE, J.; ASHER, M.; CLARA, M.; DEKOMIEN, G.; EPPLEN, J.T.; SARALEGUI, A.; SACHSER, N. Species-level differentiation of two criptic species pairs of wild cavies, genera Cavia and Galea, with a discussion of the relationship between social systems and phylogeny in the Caviinae. Can. J. Zool., v. 82 pp. 516-524, 2004.

TRIVERS, R. L. Parental investment and sexual selection. In: CAMPBELL, B. (ed.). Sexual selection and the descent of man. Aldine, Chicago, 1972.

VERNER, J. Evolution of polygamy in the long-billed marsh wren. Evolution, v. 18, pp.252-261, 1964.

VON HOLST, D. The concept of stress and its relevance for animal behavior. Advances in the Study of Behavior, v. 27, p. 1-131, 1998.

WEBSTER, D. G., WILliAMS, M. H., DEWSBURY, D. A. Female regulation and choice in the copulatory behavior of montane voles (Microtus montanus). Journal of Comparative and Physiological Psychology, v. 96, n. 4, p. 661-667, 1982.

WEIDT, A.; HOFMANN, S. E.; KÖNIG, B. Not only mate choice matters: fitness consequences of social partner choice in female house mice. Animal Behaviour, v. 75, n. 3, p. 801-808, 2008.

WEIR, B. J. Notes on the origin of the domestic guinea pig. Symp. Zool. Soc. Lond., v. 34, pp. 437-446, 1974. 
WHEATERHEAD, P. J.; ROBERTSON, R. J. Male behavior and female recruitment in the redwinged blackbird. Wilson Bull., v. 89, pp. 583-592 1977.

WHEATERHEAD, P. J.; ROBERTSON, R. J. Offspring Quality and the Polygyny Threshold: "The Sexy Son Hypothesis". Am. Nat., v. 113, n. 2, pp. 201-208.

WHITEHEAD, H. SOCPROG programs analysing animal social structures. Behavioral Ecology Sociobiology, v. 63, p. 765-778, 2009.

WISZNIEWSKI, J.; BROWN, C.; MÖLLER, L. M. Complex patterns of male alliance formation in a dolphin social network. Journal of Mammalogy, v. 93, n. 1, p. 239$250,2012$.

WOODS, C. A; KILPATRICK, C. W. Infraorder Hystricognathi. Em: Wilson D. E; Reeder, M. (Ed). Mammal species of the world. 3th. ed. Baltimore:JHU Press, 2005. 142p. 